This report begins with an overview of the Data Acquisttion System (DAS). which supports several of PPPL's experimental devices. performance
measurentents which were taken on DAS and the tools used to make them are then
described.

\title{
DISCLAIMER
}

\begin{abstract}
This report was prepared as an account of work sponsored by an agency of the United Stutes Govemment. Neither the United Slates Govetoment nor any agency thereof, nor any of their employee, makes any wertanty, expres or impliod, or assumes any legal liability or responsibility for the sccurtey, completenets, or usefulacse of any informetion, apparatus, product, ar proces discloed, or represents thet its use would not infringe privately owned rights. Refer- ence herein to any specific ocnmercial product, moceses or service by trade name, trademark, manulacturer, or otherwite does nol recesurily constitute or imply its endorsement, recommeadation, or favoring by the Uniled States Government or any agency thereof. The views aed opinion of autbors expresued berein do not necesenrily state or reflect those of the United States Goverameat or my agency thereof.
\end{abstract}




\subsection{INTRODUCTION}

The data acquisition, analysis, and archiving facilities for a number of PPPL experimental machines are provided by a network of romputers known as the Data Acquisition Sygtem (DAS). DAS is based on two families of computers manufactured by the Digital Equipment corporation (DEC) = a 36-bit DECsystem-10 (PDP-i0) mainframe, and several 16-b1t PDP-11 minicomputers.

The DAS data acquisition system is composed of a three-level computer network. The top level consists of a DECsystem-10 computer with a KL10 CPU zunning the TOPS-10 operating system. This system provides the major data archiving and analysis facilities. The second level is composed of five PDPm $11 / 34$ computers running the RSX-11M operating system, connected to the PDP-10 through a DMAlO direct memory access interface. These computers provide the major data acquisition capabilities. The third level is composed of various computers from other PDP-11/34's to PDP-11/04's, a PDP-B, a Data General NOVAII, and nonintelligent devices such as Pulse Height Analyzers. Some of these computers run the RSX-11M operating system, while others are standalone. These systems provide specialized data acquisition facilities. A VAX-11/730 is also connected to this network. Figure 1 shows a diagram of the current DAS configuration.

The TOPS-10 and RSX-11M operating systems have been modified to provide task-to-task communication facilities between the computers. Data are acquired on. the PDP-11's, and archived and analyzed on the PDP-10. Each system on the first and second levels has a scheduler program which runs the appropriate acquisition and analysis programs in response to timing signals from the main experiment timers. File traffic between the PDP-10 and PDP-1I's is processed by a program called FTU (File Transfer Utility) running on the PDP-10. 
The major portion of the data acquired by the second level computers is by means of camac instrumentation highways. The CAMAC (Computer Automated Meagurement and Control) Instrumentation system consista of standarized modules (andog-to-digital converters, histograming memories, ete.) and the dataway which interconnecto thra. Two of the second-level gystems (CPU1 and CPU2) have a PPPLbuilt communication device called the Parallel Data channel (PDC). This device connects up to elght third-level devices to a second-level host system.

The basic machine operation cycle starts with a timex pulse at T-30 seconds. This triggers the second-level computers to start running Initialization programs which arm the various data acquisttion ingtrumentation aystems. The PDP-10 18 also notifled of this event and performs its own initialization process. At To, the machise is pulsed, generating a plasma dischaxge which is recorded by the data acquisition hardware. Approximately two seconds after this, the second-level computers recelve another tining signal which causes a series of acquifition programs to be run which read out the data stored in the acquisition hardware systems and archise it on the PDP10. The PDP-10 is also notified of this event and, as the data files become available, the approprlate analyals programs are run. The analysis programs generate a serieg of graphs which are dieplayed on gcreens in the control room.

\subsection{DAS LOAD GROHTH}

The DAS gystem currently gupports three active experimental machines: the Princeton sarge Torue (PLT), the Pre-Spheromak (PS), and the Spheromak (51). The Pololdal Divertor Experiment (PDX), which recently shut down, was the heaviest user. The Radis Frequency Teat Facility (RFTF) is about to begin 
operations, and PDX is undergoing modiflcations before being brought back online. This will give a total of flve on-line experiments. Table 1 shows a summary of some typical PLT and PDX experiment runs and the computer resources (PDP-10) used. Figures $2(a-i)$ and $3(a-i)$ show a graphic representation of this data. In Figs. 2a and 3a, Archive Profile is the amount of data archived in Megabytes. Notice in Figs. 2 and 3 that the axes in the corresponding graphs are not all to the same scale.

The growth in the DAs load is not only due to the increase in the number of experiments which must be supported; but, also, as experimental operations progress, the number of diagnostics on the machines and the amount of data they take tends to increase substantially. In $198 \mathrm{I}$ PDX acquired approximately 1.2 Megabytes of data per shot with 18 diagnostics. By 1982 the PDX Load had increased to 1.7 Megabytes of data per shot with 23 diagnostics. This represents an increase of almost 428 . The DAS system currently acquires approximately 2 Wegabytes of data under normal load conditions. The maximum Load to date has been approximately 2.8 Megabytes. system degradation begins to manifest itself when these load ievels are approached.

Future load levels wiil be compounded by the prospect of concurrent operation of several machines. The DAS system was designed with the guaranty that only one machine would run at a given time. This has teen voided by the need to run $\mathrm{Sl}$ and RFTF concurrently with PLT. System software modifications will be required in order to support this load. This will be difficult to accomplish due to staff reductions. In 1980 there were four systems programmers supporting the DAS system. This has been reduced to one full-time systems progzammer with some support from others in the group. 
The extreme demands about to be placed on an alfeady overloaded system have necessitated a system performance study of DAS in order to identify curcent limitations and determine optimum hardware and software upgrades.

\subsection{SYSTEM PEREORMANCE STUDY}

The purpose of the system performance study is to measure the current utilization of the DAS system so that optimizations can be performed, and needed additiona 1 resources identified.

3.1 System Performance study

Itens Measured

The items measured were:

1. CPU utilization,

2. Memory utilization,

3. Disk chanrel utillzation,

4. Monitor overhead.

\subsection{Measurement Tools}

The following tools were used to take the performance measurements:

1. SYSTAT

This program displays a wide variety of system information including the status of all jobs, high segments, swapping space, f $\ddagger$ le structures, etc.

2. SYSDPY

This program displays the same information as SYSTAT in the form of a dynamically updated video screen. Only the data that change are updated. The information can also be logged in a disk file. 
3. LINES/LNSFPT

LINES is a program that records the monitor performance data at one-minute intervals, LNSRP? is a progran that formats the data from LINES to provide detailed reports. The reports available include data on resource ut11ization, processor queue data, special queve data, and class percentages.

4. SNOOPY/TATTLE

SNOOPY is a program which collects gtatistics of where a program spent coy time. It can collect data on an individual job, on all jobs, and on the monitor and/or interrupt service routines. TATTLE is a program which processes the data output by SNOOPX.

5. KLBPP.

This is a program to control the gathering of general background system performance statistics of a 7-series Tops-Io monitor via the performance meter available on all KL=10 CPUs.

6. CPU

This program shows the cache hit ratio vs idze time.

7. DBUSY

This program tells the length of the position wait and transfer wait queues. 
B. DDB4
This program shows flle activity.

9. THACK

This program monitors the progress and performance of individual jobs and the performance and utilization of an entire system.

\subsection{Standard Load}

In order to measure system performance, a standard load system was developed. This system allowed selected system parameters, such as memory and disk configurations, to be varied while płacing a constant and repeatable load on the system. The standard load system can be set to simulate any desired combination of archived data volume, number of acguisition tasks, and acquisitic:. data rate.

The standard load system is composed of four software components:

\section{Timer/schedular program}

This program simulates the experiment timer and also schedules the data acquisition simulation programs in response to the simulated timer events. One copy of this program funs on one or more of the second-level systems. If more than in the simulation, one is selected to be the master timer and the others are slaved to it. The master timer also synchronizes the PDP-10 real-time system. 
2. Data Acquisition simulation program

Multiple copies of this program are installed in the RSx systems under unique task names. Each task name corresponds to a simulated diagnostic. The number of channels witten, the size of each channel, and the $I / O$ rate can be controlled. The simulated analysis load on the PDP-10 can be controlled by varying the above three parameters. As each simulated diagnostic task completes, it triggers its corresponding simulated analysis program on the pop10.

3. Acquisition Control program

This interactive program sets the number of channels to be archived, the size of the channels, and the I/O rate. It can be run on any of the rSx computers.

4. Data Analysis simulation program Multiple copies of this program reside on the PDP-10. When triggered to run by its corresponding acquisition program, this program reads the appropriate archived data file in the following manner: four reads of $2 \pi$ points each are taken from channel 1 and a plot is generated; then, one read of $4 \mathrm{~K}$ points is taken from each of channels 1 through 10 and a second plot is generated. This gives a total of $4 B K$ data points accessed. Figure 4 (a-b) shows an example of these plots. 


\subsection{Simulation Tests}

The simulation tests were performed with the DAS system in standalone mode. Test were performed with memory configurations of $512 \mathrm{~K}$ and 1 Megaword on the PDP-10. Tests were also performed with an RP06 disk drive and an RP07 disk drive as the primary archiving device. The goal of the tests was to determine the saturation areas of the PDP-10.

\subsection{Measurement Criteria}

Digital Equipment Corporation has established the following criteria as a guideline in determining pop-10 system saturation levels:

\section{Processor saturation}

The central processor is considered to be saturated if one or more of the following conditions are met:

1. The percent idle time is 0 .

2. The percent overhead time is greater than $20 \%$.

3. The number of jobs in run queues is greater than 7.

2. Memory saturation

The main memory is considered to be saturated if one or more of the following conditions are met:

1. The number of core blocks swapped per second is greater than 500.

2. The percent lost time is greater than 5\%.

3. The active swapping rat lo is greater than 2.0 . 
3. Disk and channel saturation

Disk saturation is determined by observing saturation at the disk unit level or a uniform load acrogs all "Public" units. This is determined with the SYSTAT program. Channel saturation is determined by observing the length of the transfer wait queues with the TRACK and DBUSY programs.

\subsection{RESULTS}

The results of the data acguired for the performance study are discussed below.

\subsection{Memory utilization}

Table 2 shows a sumary of data from the LINES program for July 26 and July 27, 2983. On July 26, the DAS DECsystem-10 was configured with 0.5 Megaword of memory. On July 27, the system was running with 1 Megaword. The numbers in parentheses are peak values, the lower numbers are the average values. The system was taking 0.8 Megabytes of data per shot on both days. Eigures $5(a-h)$ and $6\{a-h\}$ show the data in detail for the respective configurations. The following discussion will compare the corresponding graphs between Figs. 5 and 6 in relation to the effects of the different memory complements.

Graph (a) displays the number of jobs on the system. These were comparable on both days and vary as a function of interactive timesharing users. The number of users on the system is relatively consistent. Graph (b) shows the CPU utilization percentage. In Fig. 56, Hith 0.5 Megaword of memory, the average CPU utilization is 70 . In Figure 6b, with 1 
Megaword of memory, it is 1008 . We believe that the CPU utilization with the 1 Megaword system is most likely due to a memory diagnostle or some other activity on the system. We cannot attribute the increase in cPu utilization to the increase in the memory.

Graph (c) shows the monitor overbead in percent. The monitor overheac did not change appreciably with the change in memory size. since the monitor is performing the same functions, this is to be expected.

Graph (d) shows the number of disk blocks read and written per minute. This also is comparable on both days; and since the archiving load is the same on both days, this result is expected.

Graph (e) shows the number of 128 word core blocks swapped per minute, that is, the swapping rate. As can be seen, with 0.5 Megaword of memory, the swapping rate averages nearly 10,000 blocks per minute with a peak of 35,000 blocks per minute. This is an average of 167 blocks per second with a peak of 583 blocks per second. With 1 Megaword of memory, swapping has been reduced to an average of 1,000 blocks per minute with a peak of a,000 blocks per minute. That converts to 17 blocks per srcond with a peak of 133 blocks per second. The additional 0.5 Megaword of memory has reduced swapping by an average of $90 \%$. It should be noted that with a heavier load, swapping would be considerably higher, which makes additional memory even more important.

Graphs (f), (g), and (h) show the percent buffer space, percent 4-word core blocks, and the percent swapping space used, respectively. There is no appreciable change in any of these parameters.

A similar memory experiment was performed on the User service Center (USC), another DECs;stem-10 installation at PPPL. On July 25, 1983, the USC was configured with 0.5 Megaword of memory. At 2800 hours, the system was configured with 1 Megaword of memory. The system ran with I Megaword until 
1900 hours on July 26, when It was conflgured back to 0.5 Magaword. The aygten $x$ an with 0.5 Megaword on July 27. Table 3 ghowa a sumary of the resu?ts, Flgures $7(a-1),, B(a-h)$, and $9(a-h)$ whow the detarlad data for the conflguration of JuIy 25 , July 26 , and July 27 , respectively. A memory exerciser alagnostic was run on Jüy 26 between 1400 and 1500 hourg. The impact of this progran is clearly evijent in Fig. B. The overall reaults of the usc memory test are comparable to the teat on DAs. swapplng was nearly eliminated with the additional menory.

\subsection{Standard Load simulation}

A series of tegts were run with the standard load simplation oystem. These tests measurea system performance under varying simulated load conditions and also measured the effect of using an RP07 disk drive ag the primary archiving device as opposed to an RP06 alsk. The RP07 ls a nonremorable winchester diak arfve with a higher recording density and fagter transfer speed than the removable pack RP0. Also considered ig an actual PLT expertmental shot. The statistics for data rates of 0.57 Megabyte, 0.93 Megabyte, 1.12 Megabyte, 3.55 Megalytes (RP06), and 3.65 Megabytes (PP07) are shown in Eigs. 10, 11, 12, 13, and 14, respect1vely, Tables 4 through B show the actual diagnostics enabled and the amount of data each arohived for the respective shots. The figures show the following statistica: iale time in percent, number of Jobg in run queues. FTU memory and CFu ugage in percent, real-time job CPU usage in percent and number of real-time jobs, the number of context gwitches per second, and the number of voo (system service calla) per second. Figure $10 \mathrm{is}$ an actual PLT ohot, the others are simulasions.

Graph (a) shows the percentage of the time that the CPU was 1die, that 19, there was no job which wanted to run. This is extxemely omall in Fig.

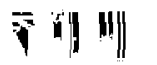


10. This can be attributed to the number of Interactive usere on the system during actial machine operation: Most terminals in the control room are lagged on to twi system running Interactive control and analysis programs. Software development and operator functions'are also active during this time." The nature of a timesharing system must be congidered when discussing CPU utizization. The nature of a job can vary from being cPu intensive to being $1 / O$ intensive. Timesharing shares the CPU among many users. A user job will Iun until either its alloted time slice has been exhaustied or it blocks for $1 / 0$. The monitor will then schedule another job from the run queve. Even if there is only a single job on the system, if that jab is CPU bound, the monitor will schedule it to run and the CPU will appear to be saturated, that is, CPU utilization wizl approach 1008. On the contrary, if that job is $I / O$ bound, CPU tutilization will appear low. Figure 10a shows that the excess CPU time not absorbed by the real-time system is being effectively utilized by the interactive jobs. Figures lla through $14 a$ show that the real-time system absorbs a longer period of the CPU as the data rate is increased. There is a much higher idle rate out:ide of the ceal-time cycle on these figures since the system was standalone during the simulation and there were no users to absorb the cpu.

Graph (b) shows the number of jots in the run queues. The same general trend as for idle time is indicated, that is, the real-time system absorbs the systems resources for a longer period of time as the load is increased. In Fig. $10 b$ the cycle ends at 80 seconds after To with a load of 0.57 Megabyte. In Fig. 11b with 0.93 Megabyte, the duration has increased by 10 seconds. The 2Ength of the run queues has also increased. This indicates that the CPU has been able to absorb the increased load. In Fig. 12b, with 1.12 Megabyte of data being schived, the run queues are comparable to those with 0.93 
Megabyte, however, the cycle has extended to 130 seconda. It has required an additional 50 seconds to process the shat. There is no run queve data available for the two tests at the 3.65 Megabytes Load level.

Graph (c) shows the number of pages of memory used by FTU and the percentage of the CPH used by ETU during the cycle. Again, as the load increasts, the resources uged increase in both magnitude and time. The cPU time used by FTo peaks at approximately 50 when the data rate reaches 0.93 Megabyte. The duration of the FTU CPU utilization increased from 50 seconds for 0.93 Megabyte to 150 seconds for 3.65 Megabytes. Figures $13 \mathrm{c}$ and $14 \mathrm{c}$ show the effect of using an RPOT disk as the primary archive device. In F1g. 14c, the RP07 has reduced the number of pages required by FTU from over 300 to approximately 250. The duration of CPU time used by Fus has been reduced from 150 seconds after T0 to 125 seconds. The RP07 has made a 208 improvement in the number of physical pages used by FTJ and the time duration that FTU is using the $\mathrm{CPU}$.

Graph (d) shows the percentage of the cav utilized by real-time jobs over the duration of a shot cycle and the number of real-time jobs in a run queue. The CPU utilization peaks at approximately 608. The number of real-time jobs peaks at four, the number of jobs cursently allocated to the real-time system. Again, the cycle is extended as the load is increased. In Fig. 13d, the real-time system is active from 140 to 200 seconds after T0. In Fig. 14d, the cycle is active from 120 to 185 seconds. The RP07 has allowed the cycle to begin and end 20 seconds earlier. Notice, however, that 60 seconds are required in both cases to process the analysis portion of the cycle. The RPO? has improved the acquisition portion of the cycle, but has not affected the analysis phase. 
Graph (e) shows the effect of the data load on context switching. No appreciable changes are evident.

Graph (f) shows the number of Uvo's (nonitor calls) per second. Again, the RP07 has made an improvement. In Fig. 14f. FTI has processed the dat. with approximately 158 fewer monitor calls than were Iiguired with the rfo6.

\subsection{Tache Memory Utilization}

The kLlo central processor includes a $2 \mathrm{k}$-word cache memory. We consistently cound a cache hit rate above 908 over the entire cycle. This indicates that the cache is being utilized effectively.

\subsection{Disk speed}

Tests were run on the DAS anc USC systems to measure the difference in disk access speed between FORTRAN and MACRO I/O routines. The tests were made writing 50 block files. It was found that with the FORTRAN language, only 1 sector per revolution could be obtained. With more than one stream, only every third sector or less could be obtained per revolution due 'o head positioning. Preallocation of disk space had no substantial effect on these results, nor dia the type of disk used. Tests were made with disk configurations of single RPO4, RP06, and RPO7 disks, and azso with two-pack RP04 stfuctures and two-pack RP06 structureb. Disk access using MACRO routines was found to be more than 30 times faster. The real-time system uses a standardized archive file format with MACRO access routines. The ratio of archive Reads/Nrites to all Reads/Nrites varies from 1:5 to 1:11 depending on the data acquisition load. Tables 9,10 , and 11 show the data from these tests. Table $g$ shows the results of the FORTRAN test runs with both preallocation and multiple streams. Table 10 shows tests of the MaCro archive 
read routines to different disk structures. DSKB consiats of two RP04 disk drives, DSKC is the RP07, and PKA is an RP06. These tests read the entire filt in a single read. As can be seen, there is no appreciable difference in speed between the RP04 and RP06. The RP07, however, is more than twlce as fast. Table 11 shows a similar test except the file 13 read in three segments. The speed advantage of the RP0T is diminished as the size of the read is decreased.

Figures 15 and 16 show the position wait and Transfer Wait queues, respectively, for PLT shot 99572 taken on Ju1y 27, 1983. The archive rate was 0.7 Megabyte. Figure 15 shows that the Position Wait queue had multiple requests pending over most of the cycle. At the peak at $\mathbf{4 0}$ seconds after To, there were seven requests in the queve. The Transfer walt queue shown in Fig. 16. however, never has more than cne request in it. This indicates that most of the time spent waiting for the disk is involved in head positioning. The RP03 has twice the capacity of the RPO6 with a higher recording density. Therefore, an RP07 can fit more data onto a track and has to reposition less.

\subsection{CONCLUSIONS}

The experimental devices supported by the DAS syster are about to be expanded which wil2 considerably increase the amount of data generated. New devices are also anticipated. The DAS system is cuzrently saturated and casnot support a greater load without additional resources. Nonstandard systems must be standardized to facilitate support. Weaknesses must be identified and eliminated. Adequate hardware resources must be acquired in order to provide a reliable and stable system. 


\subsection{ACKNOWLEDGMENTS}

The authors would like to thank P. Roney for providing the analysis simulation program and the DAS operators for their support during this project. Th1s work supported by U.S. Department of Energy Contract Nir. DE-ACO2-76-CHO-3073. 


\section{FIGURE CAFPIONS}

FIG. 1 DAS computer network configuration.

FIG. 2a-1 Typical RLT shot

PIT data archive on 08-1ay-82

132 ghotg taken (76653-76800)

Peak of 17 diagnogtica at $16: 14$

Total archived; 135.4 Megabytes

FIG. 3a-i Typlcal PDX shot.

PDX data archived on 26-May-82

66 shots taken (50642-50758)

Peak of 23 diagnostics at $14: 53$

Total archived: 95.3 Megabytes

FIG. 4 Sample plots from analyeis simulation program.

FIG. 5 DAS performance otatistics with 0.5 segaword maln meniory $(7 / 26 / 83)$.

FIG 6 DAs performance statisties with 1 kegaword ma1n memory $(7 / 27 / 83)$.

FIG. 7 JSC performance statistics with 0.5 Megaword main memory $(7 / 25 / 83)$.

FIG. 8 USC performance statistics with 1 Megaword main memory $(7 / 26 / 83)$.

FIG. 9 USC performance statistics with 0.5 Negaword main memory $(7 / 27 / 83)$. 
FIG. 10 PLT $1211,16-$ Aug-83 18:34, 3-minute cycle, 1 Megaword memory, 0.57 Megabyte of data, to diagnontics, 51 jobs.

FIG. 11 Test shot" 83204, 17-Aug-83 22:22, 3-minute cycle, 1 Megaword memory, 0.93 Megabyte of data, 10 diagnostics, $3 E$ jobs.

FIG. 12 Test shot* 83219, 17-hug-83 18:34, 3-minute cycle, 1 Megaword menory, 1.12 Megabyte of data, 16 diagnostics.

FIG. 13 Test zhot: 83287, 19-Aug-83 02:02, 3-minute oycle, 1 Megaword memory, 3.65 Megabytes of data, 15 diagnogticB, RP06.

FIG. 14 Test shot\# 83298, 19-Aug-83 05:37, 3-minute cycle, i Megaword menory, 3.65 Megabytes of data, 15 diagnootios, RPD7.

FIG. 15 Length of position Hait queue (PLT Bhot" 99572)

FIG. 16 Length of Transfer wait queue (PLT ghot: 99572) 
TABLE 1

DAS Performance Statistics

\begin{tabular}{|c|c|c|c|c|c|c|c|}
\hline & $\begin{array}{c}\text { PLT } \\
0 \text { Buay82 }\end{array}$ & $\begin{array}{c}\text { PnX } \\
26 \text { kay82 }\end{array}$ & $\begin{array}{c}\text { PDX } \\
\text { S1 } \\
\text { 30Junes3 }\end{array}$ & $\begin{array}{c}\text { PLT } \\
05 \text { Jul83 }\end{array}$ & $\begin{array}{c}\text { PLT } \\
\text { 06Ju183 }\end{array}$ & $\begin{array}{c}\text { PLT } \\
\text { 07JuI83 }\end{array}$ & $\begin{array}{c}\text { (1MN) } \\
\text { PLT } \\
203 u 183\end{array}$ \\
\hline $\begin{array}{l}\text { Hours of } \\
\text { Interest }\end{array}$ & $\begin{array}{l}1000: \\
1600\end{array}$ & $\begin{array}{l}1400: \\
1000\end{array}$ & $\begin{array}{l}1300: \\
1600\end{array}$ & $\begin{array}{l}1000= \\
1400\end{array}$ & $\begin{array}{l}1000: \\
1400\end{array}$ & $\begin{array}{l}1000= \\
1400\end{array}$ & $\begin{array}{l}1000: \\
1400\end{array}$ \\
\hline $\begin{array}{l}\text { Megabytes } \\
\text { Per Shot }\end{array}$ & $\begin{array}{r}(1.3) \\
1.05\end{array}$ & $\begin{array}{c}(2.1) \\
1.7\end{array}$ & $\begin{array}{rr}S 1 & 0.02 \\
\text { PLT } & 0.65\end{array}$ & & & $\begin{array}{rr}\text { S1 } & 0.45 \\
\text { PLT } & 0.38\end{array}$ & \\
\hline $\begin{array}{l}\text { Number } \\
\text { Jobs }\end{array}$ & $\begin{array}{c}(44) \\
42\end{array}$ & $\begin{array}{c}(70) \\
63\end{array}$ & $\begin{array}{l}(61) \\
57\end{array}$ & $\begin{array}{c}(60) \\
50\end{array}$ & $\begin{array}{c}(56) \\
50\end{array}$ & $\begin{array}{c}(70) \\
60\end{array}$ & $\begin{array}{c}(58) \\
54\end{array}$ \\
\hline $\begin{array}{l}8 \text { CPU } \\
\text { Time Used }\end{array}$ & $\begin{array}{c}(85) \\
65\end{array}$ & $\begin{array}{c}(100) \\
95\end{array}$ & $\begin{array}{c}(100) \\
80\end{array}$ & $\begin{array}{c}(100) \\
75\end{array}$ & $\begin{array}{c}(100) \\
60\end{array}$ & $\begin{array}{c}(900) \\
92\end{array}$ & $\begin{array}{c}(100) \\
80\end{array}$ \\
\hline $\begin{array}{l}\text { Monitor } \\
\text { Overhead }\end{array}$ & $\begin{array}{c}(14) \\
9\end{array}$ & $\begin{array}{c}(17) \\
14\end{array}$ & $\begin{array}{c}(20) \\
13\end{array}$ & $\begin{array}{l}(18) \\
10\end{array}$ & $\begin{array}{c}(18) \\
8\end{array}$ & $\begin{array}{c}(20) \\
14\end{array}$ & $\begin{array}{c}(14) \\
11\end{array}$ \\
\hline $\begin{array}{l}\text { DSK Blks } \\
\text { R/W per min }\end{array}$ & $\begin{array}{c}(4000) \\
2800\end{array}$ & $\begin{array}{c}(4200) \\
3800\end{array}$ & $\begin{array}{c}(6000) \\
3000\end{array}$ & $\begin{array}{c}(9000) \\
1600\end{array}$ & $\begin{array}{c}(5000) \\
1500\end{array}$ & $\begin{array}{c}(10000) \\
2500\end{array}$ & $\begin{array}{c}(7800) \\
2300\end{array}$ \\
\hline $\begin{array}{l}\text { Core Blks } \\
\text { Swapped } \\
\text { per min }\end{array}$ & $\begin{array}{c}(28000) \\
15000\end{array}$ & $\begin{array}{c}(55000) \\
32000\end{array}$ & $\begin{array}{c}(42000) \\
9000\end{array}$ & $\begin{array}{c}(36000) \\
5000\end{array}$ & $\begin{array}{c}(7000) \\
1500\end{array}$ & $\begin{array}{c}(40000) \\
10000\end{array}$ & $\begin{array}{c}(8000) \\
1700\end{array}$ \\
\hline $\begin{array}{l}8 \text { TTYY Buf } \\
\text { Space Used }\end{array}$ & $\begin{array}{c}(40) \\
38\end{array}$ & $\begin{array}{c}(44) \\
38\end{array}$ & $\begin{array}{c}(42) \\
38\end{array}$ & $\begin{array}{c}(38) \\
38\end{array}$ & $\begin{array}{c}(45) \\
38\end{array}$ & $\begin{array}{c}(42) \\
38\end{array}$ & $\begin{array}{c}(42) \\
38\end{array}$ \\
\hline $\begin{array}{l}\text { Monitor } \\
\text { Core Blks } \\
\text { Used }\end{array}$ & $\begin{array}{c}(18) \\
16\end{array}$ & $\begin{array}{c}(60) \\
50\end{array}$ & $\begin{array}{c}(40) \\
30\end{array}$ & $\begin{array}{l}(32) \\
25\end{array}$ & $\begin{array}{c}(17) \\
14\end{array}$ & $\begin{array}{l}(35) \\
30\end{array}$ & $\begin{array}{c}(23) \\
20\end{array}$ \\
\hline $\begin{array}{l}\text { Swap } \\
\text { Space Ūsed }\end{array}$ & $\begin{array}{c}(33) \\
28\end{array}$ & $\begin{array}{c}(25) \\
23\end{array}$ & $\begin{array}{c}(29) \\
27\end{array}$ & $\begin{array}{l}\text { (3.3) } \\
18\end{array}$ & $\begin{array}{c}(17) \\
14\end{array}$ & $\begin{array}{c}(38) \\
23\end{array}$ & $\begin{array}{c}(28) \\
16\end{array}$ \\
\hline
\end{tabular}

NoTES: Number in (, is peak value, number below is average. 
TABLE 2

DAS Performance statistics

(0.5 Megaword Memory vs 1 Megaword Memory)

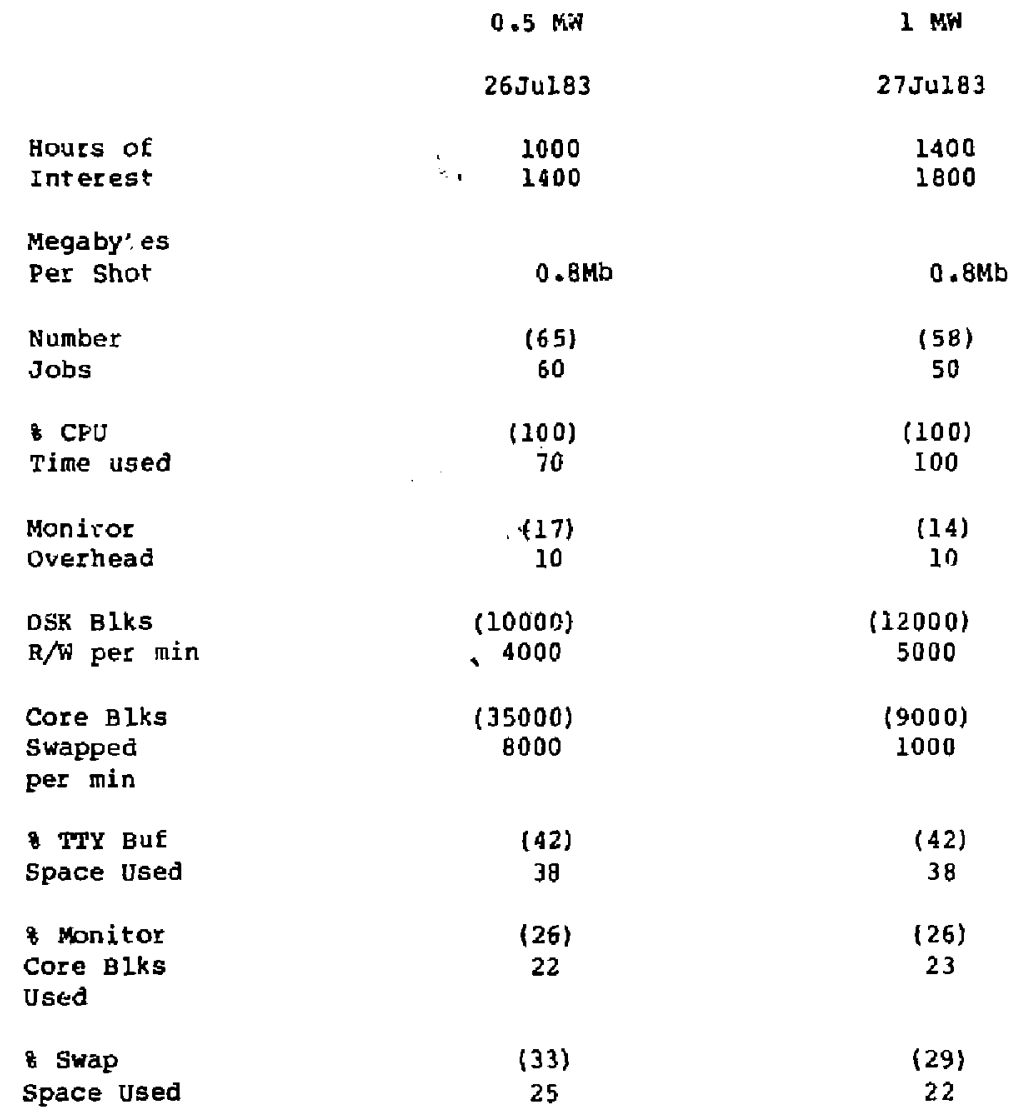

NOTES: Number in ( ) is peak value, number below is average. 
TABLE 3

USC Performance statiatics

(0.5 Megaword Menory va I Megaword Memory)

\begin{tabular}{|c|c|c|c|}
\hline & $0.5 \mathrm{MH}$ & $I M N$ & $1 \mathrm{HW}$ \\
\hline & $25 J u 183$ & $26 J u 283$ & $27 J u 1.83$ \\
\hline $\begin{array}{l}\text { Hours of } \\
\text { Interest }\end{array}$ & $\begin{array}{l}1200 \\
1500\end{array}$ & $\begin{array}{l}0900 \\
1100\end{array}$ & $\begin{array}{l}1300 \\
1600\end{array}$ \\
\hline $\begin{array}{l}\text { Number } \\
\text { Jobs }\end{array}$ & $\begin{array}{c}(82) \\
70\end{array}$ & $\begin{array}{c}(70) \\
60\end{array}$ & $\begin{array}{c}(30) \\
65\end{array}$ \\
\hline $8 \mathrm{CPO}$ & (23) & (23) & (16) \\
\hline Time used & 17 & 15 & 13 \\
\hline $\begin{array}{l}\text { DSK Blks } \\
\text { R/W per min }\end{array}$ & $\begin{array}{c}(5000) \\
3000\end{array}$ & $\begin{array}{c}(55000) \\
2100\end{array}$ & $\begin{array}{c}(5000) \\
3500\end{array}$ \\
\hline $\begin{array}{l}\text { Core Biks } \\
\text { Swapped } \\
\text { per min }\end{array}$ & $\begin{array}{c}(18000) \\
3000\end{array}$ & $\begin{array}{c}(500) \\
500\end{array}$ & $\begin{array}{c}(24000) \\
18000\end{array}$ \\
\hline $\begin{array}{l}\text { 8TTY Buf } \\
\text { Space Used }\end{array}$ & $\begin{array}{c}(48) \\
33\end{array}$ & $\begin{array}{l}42 \\
38\end{array}$ & $\begin{array}{l}42 \\
38\end{array}$ \\
\hline$\&$ Monitor & (38) & (26) & (30) \\
\hline $\begin{array}{l}\text { Core BIks } \\
\text { Used }\end{array}$ & 28 & 22 & 23 \\
\hline $\begin{array}{l}8 \text { Swap } \\
\text { Space Used }\end{array}$ & $\begin{array}{c}(2 B) \\
25\end{array}$ & & $\begin{array}{c}(28) \\
30\end{array}$ \\
\hline
\end{tabular}

NOTES: Number in $($ ) is peak value, number below is average. 
TABLE 4

Shot Summary for PLT Shot 1211, 16-Aug-83 18:34, 0.57 Megabyte of data 1004 DSK B2ks (0.578304 Mb) For Shot 01211 on 16-Aug-83, 18:34 - 10 Diags.

\begin{tabular}{|c|c|c|c|c|c|c|}
\hline 257 & BLKS & 66,4777 & $\mathbf{L V}$ & FLT & - & Low Energy Neutral System \\
\hline 173 & BLKS & 66.5053 & Nh & PLT & - & Microwaye Scattering \\
\hline 135 & BLKS & 66,4177 & $C Y$ & PLT & - & Cyclotzon Erission \\
\hline 133 & BLKS & 66,4030 & AH & PLT & - & ADH ADC 32 Channels \\
\hline 115 & BLKS & 66,4761 & LH & PLT & - & Lower Hybrid Heating \\
\hline 76 & BLKS & 66,4074 & BA & PLT & - & Bolometer Array \\
\hline 6.7 & BLKS & 66,5507 & $\mathbf{T F}$ & PLT & - & Toroidal Field Monitor \\
\hline$\exists 1$ & BLKS & 66,5524 & TS & PLT & - & TV Thomson scattering \\
\hline 14 & BLKS & 66,5123 & NT & PLT & - & Neutron Temperature \\
\hline 3 & BLKS & 66,4251 & DX & PLT & - & Datax Replacement \\
\hline
\end{tabular}


TABLE 5

Shot Summary for Test Shot B3204, 17-Aug-83 22:22, 0.93 Megabyte of Data 1620 DSK BLKS (0.93312 Mb) FOR SHOT 83204 ON 17-Aug-83 22:22 - 10 Diags.

\begin{tabular}{|c|c|c|c|c|c|c|}
\hline 162 & BLKS & 66,5456 & $\mathbf{s x}$ & PDX & - & Spectroscopy \\
\hline 162 & BLKS & 66.5236 & PI & PDX & - & Pellet Injection \\
\hline 162 & BLKS & 66,5047 & MS & PDX & - & Mlcrowave Scattering \\
\hline 162 & BLKS & 66,5030 & MD & PDX & - & Machine Diagnostics \\
\hline 162 & BLRS & 66,4774 & LS & PDX & - & CO2 Laser scattering \\
\hline 162 & BLKS & 66,4566 & IN & pDX & - & MHD Instabllity \\
\hline 162 & BLKS & 66,4444 & GR & PDX & - & Grating Polychrometer \\
\hline 162 & BLKS & 66,4433 & GI & PDX & - & Gas Injection \\
\hline 162 & BLKS & 66,4245 & DT & $\mathrm{PDX}$ & - & Diagmagnetic Diagnostic \\
\hline 162 & BLKS & 66,4243 & DR & PDX & - & Plasma Disruption \\
\hline
\end{tabular}


TABLE 6

Shot Summary for Test Shot 83219, 17-nug-83 23:28, 1.12 Magabytes of data 1952 DSK BLKS (1.124352 Mb) FOR SHOT B3219 ON 17-Aug-83 23:28 - 16 Diags.

\begin{tabular}{|c|c|c|c|c|c|c|}
\hline 122 & BLKS & 66,5644 & $\mathrm{vi}$ & PDX & - & Vistble Acquistition \\
\hline 122 & BLXS & 66,5632 & vc & PDX & - & Vistal Continuum \\
\hline 122 & BLKS & 66,5512 & $\mathrm{TI}$ & PDX & - & Charge Exchange \\
\hline 122 & BLKS & 66,5456 & sx & PDX & - & Spectroscopy \\
\hline 122 & BLKS & 66,5236 & RI & PDX & - & Pellet Injection \\
\hline 122 & BLKS & 66.5110 & NI & PDX & - & Neutron Ion Temperature \\
\hline 122 & BLKS & 66.5054 & $M x$ & PDX & - & Microwave Interferometer \\
\hline 122 & BLKS & 66,5051 & MU & PDX & - & Multichannel spectrometer \\
\hline 122 & BLKS & 66.5047 & MS & PDX & - & Microwave Scattering \\
\hline 122 & BLKS & 66.5030 & $M D$ & PDX & - & Machine Diagnostics \\
\hline 122 & BLKS & 66.4774 & LS & PDX & - & $\mathrm{CO}_{2}$ Laser scattering \\
\hline 122 & BLKS & 66.4566 & IN & PDX & - & MHD Instability \\
\hline 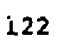 & BLKS & 66,4444 & GR & PDX & - & Grating Polychrometer \\
\hline 122 & BLKS & 66,4433 & GI & PDX & - & Gas Injection \\
\hline 122 & BLKS & 66,4245 & DY & PDX & - & Diagmagnetic Diagnostic \\
\hline 122 & BLKS & 66,4243 & DR & PDX & - & Plasma Disruption \\
\hline
\end{tabular}


THBISE 7

Shot stumary for rest shot 83287, 19-hug-83 02:02,

3.65 regabytes of ants, Ro06

6345 DSK BLKS (3.65472 Mt) SOR SHOT B3287 ON 17-hug-83 2:02 - 15 Dic,3.

\begin{tabular}{|c|c|c|c|c|c|c|}
\hline 423 & BLKS & 66,5644 & VA & PDX & - & Vialble requiaition \\
\hline 423 & BITS & 66,5512 & $\mathbf{T I}$ & PCI & $=$ & Charge Excharge \\
\hline 423 & BLXS & 66,5456 & sx & PLX & - & Spectroseopl \\
\hline 423 & BLKS & 66,5236 & $\mathbf{P I}$ & PDX & - & Pellet Injection \\
\hline 423 & BLRS & 66,5226 & PA & PDX & $\boldsymbol{m}$ & Probe Acquisition \\
\hline 423 & ELNS & 66,5051 & $\mathrm{MU}$ & PDX & - & Multichannel Spectrometer \\
\hline 423 & BLKS & 66,5047 & MS & PDX & - & Microwave scattering \\
\hline 423 & BLXS & 66,5030 & MD & PDX & - & Buchine Diagnostics \\
\hline 423 & BLKS & 66,4774 & LS & PDX & - & $\mathrm{CO}_{2}$ Inser sct ttering \\
\hline 423 & BLKS & 66,4576 & IV & PDX & - & Infrared Video Camera \\
\hline 423 & BLKS & 66,4566 & IN & PDX & - & MHD Tnstability \\
\hline 423 & BLKS: & 66,4444 & GR & PDX & - & Grating Polychrometer \\
\hline 423 & BLKS & 66,4433 & $\mathbf{G I}$ & PDX & - & Gas Injection \\
\hline 423 & BLWS & 66,4245 & $\mathbf{D T}$ & PDX & - & Diagmagnetic Diagnostic \\
\hline 423 & BLKS & 66,4243 & DR & PDE & - & Plána Disruption \\
\hline
\end{tabular}


TABLE 8

Shot Sumnary for Test Shot 83298, 19-Aug-83 05:37,

3.65 Megabytes of Data, RP07

6315 DSK BLKS (3.65472 Mb) FOR SHOT 83298 ON 19-Aug-83 5:37 - 15 Diags.

\begin{tabular}{|c|c|c|c|c|c|c|}
\hline 423 & BLKS & 66,5644 & VM & PDX & - & Visible Acquisition \\
\hline 423 & BLKS & 66,5512 & TI & PDX & - & Charge Exchange \\
\hline 423 & BLKS & 66,5456 & sx & PDX & - & spectroscopy \\
\hline 423 & BLK5 & 66.5236 & PI & PDX & 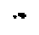 & Pellet Injection \\
\hline 423 & BLKS & 66,5226 & PA & PDX & - & Probe Acquisition \\
\hline 423 & BLKS & 66,5051 & MU & PDX & - & Suztichannel Spectrometer \\
\hline 423 & BLKS & 66,5047 & MS & PDX & - & Microwave Scattering \\
\hline 423 & BLKS & 66,5030 & MD & PDX & - & Machine Diagnostics \\
\hline 423 & BLKS & 66.4774 & LS & PDX & - & $\mathrm{CO}_{2}$ Laser scattering \\
\hline 423 & BLKS & 66,4576 & IV & PDX & - & Infrared Video Camera \\
\hline 423 & BLKS & 66,4566 & IN & PDX & - & MHD Instability \\
\hline 423 & BLKS & 66,4444 & GR & PDX & - & Grating Polychrometer \\
\hline 423 & BLKS & 66,4433 & GI & PDX & - & Gas Injection \\
\hline 423 & BLKS & 66,4245 & DT & PDX & - & Diagmagnetic Diagnostic \\
\hline 423 & BLKS & 66,4243 & DR & PDX & - & Plasma Disruption \\
\hline
\end{tabular}


TABLE 9

FORTRAN Disk Measurementa

DAS standelone 7-Ju2y-g3

Summary

50 Block

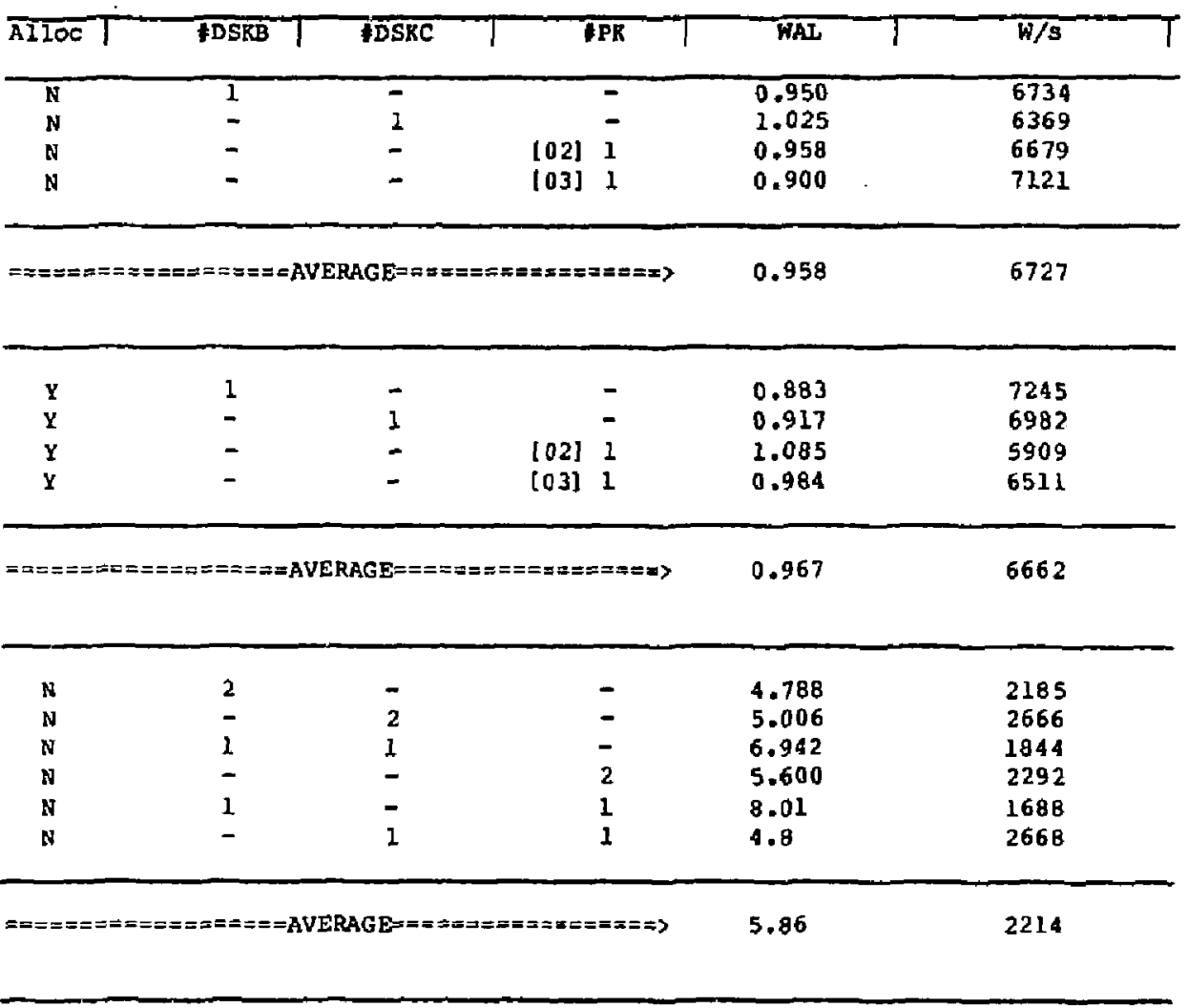


TABLE 10

Archive Software Disk Measurements (Single Read)

DAS system Per formance

Disk Measursments Using The Archive Random Access Routines

NEDNESDAY JULY 20, 1983

8:48-8:49a.m.

\begin{tabular}{|c|c|c|c|c|c|}
\hline \multicolumn{4}{|c|}{ NO. OF STREAMS TO A DISK } & WALL TIKE & WORDS RBAD \\
\hline \multicolumn{2}{|c|}{ DSKB } & DSKC & $\mathrm{PR}^{*}$ & (SECS) & (WORDS/SEC) \\
\hline $2 \cdot 25: 1$ & $\begin{array}{l}1 \\
- \\
-\end{array}$ & $\begin{array}{l}\overline{1} \\
-\end{array}$ & - & $\begin{array}{l}0.294 \\
0.133 \\
0.300\end{array}$ & $\begin{array}{l}117,894 \\
260,160 \\
115,865\end{array}$ \\
\hline \multicolumn{4}{|c|}{$===========$ AVERAGES $=========\Rightarrow>>$} & 0.242 & 164,640 \\
\hline $\begin{aligned} 2 \cdot 2: 1 & =\Rightarrow \\
& =\Rightarrow\end{aligned}$ & $\begin{array}{l}2 \\
- \\
- \\
1 \\
- \\
1\end{array}$ & $\begin{array}{l}- \\
2 \\
- \\
1 \\
1 \\
-\end{array}$ & $\begin{array}{l}- \\
- \\
- \\
1 \\
1\end{array}$ & $\begin{array}{l}0.550 \\
0.250 \\
0.550 \\
0.556 \\
0.550 \\
0.557\end{array}$ & $\begin{array}{l}126,138 * \\
227,504 * \\
126,138 * \\
124,701 \\
126,138 * \\
124,901\end{array}$ \\
\hline \multicolumn{4}{|c|}{$============$ AVERAGES $==\ddot{=}======>>$} & 0.502 & 150,953 \\
\hline $\begin{aligned} 2 \cdot 16: 1 & \Rightarrow \\
& \Rightarrow\end{aligned}$ & $\begin{array}{l}3 \\
- \\
- \\
1\end{array}$ & $\begin{array}{l}- \\
3 \\
- \\
1\end{array}$ & $\begin{array}{l}- \\
- \\
3 \\
1\end{array}$ & $\begin{array}{l}0.828 \\
0.383 \\
0.828 \\
0.825\end{array}$ & $\begin{array}{l}125,753 \\
271,514 \\
125,726 \\
126,151\end{array}$ \\
\hline \multicolumn{4}{|c|}{$==== \pm= \pm======$ AVERAGES $===== \pm= \pm==>>$} & 0.716 & i 62,362 \\
\hline
\end{tabular}

HOTES :

170 Block archive file

* Times ideritical for all four (4) runs.

HPQ=7 Times all close ( $28 \%$ ) subritted.

DSRPRI=3 By batch. Approx 1 min elapsed time. With new memory on multiple streans, read entire file at once with one copy of disk read prog. 
TABLE 11

Archive Software Disk Measurements (Multiple Reads)

DAS System Performance

Disk Measurements Dsing The Archive Random Access Routines

TUESDAY, JULY 27, 1983 7:10 A.M.

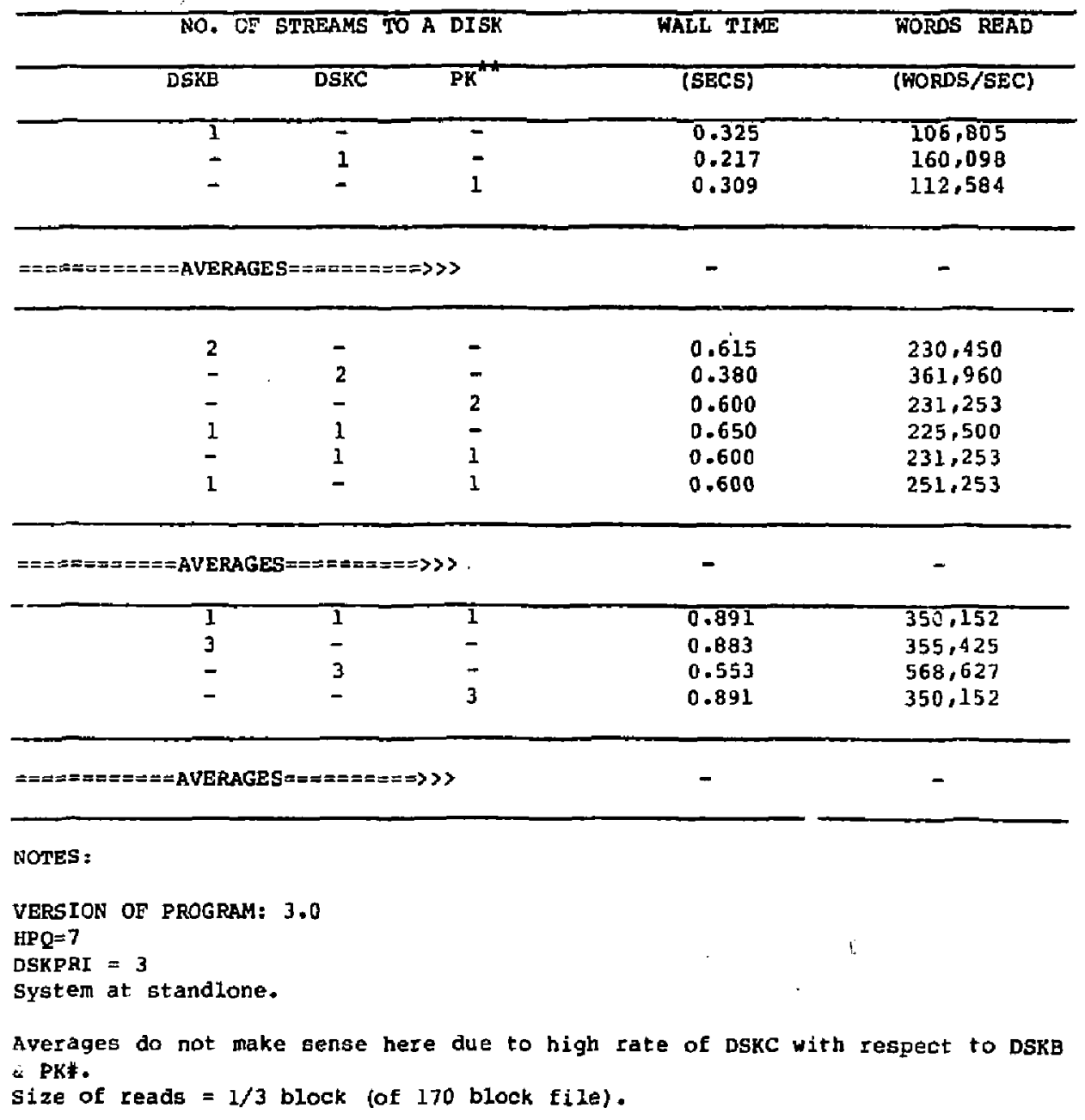


DAS COMPUTER NETHORK

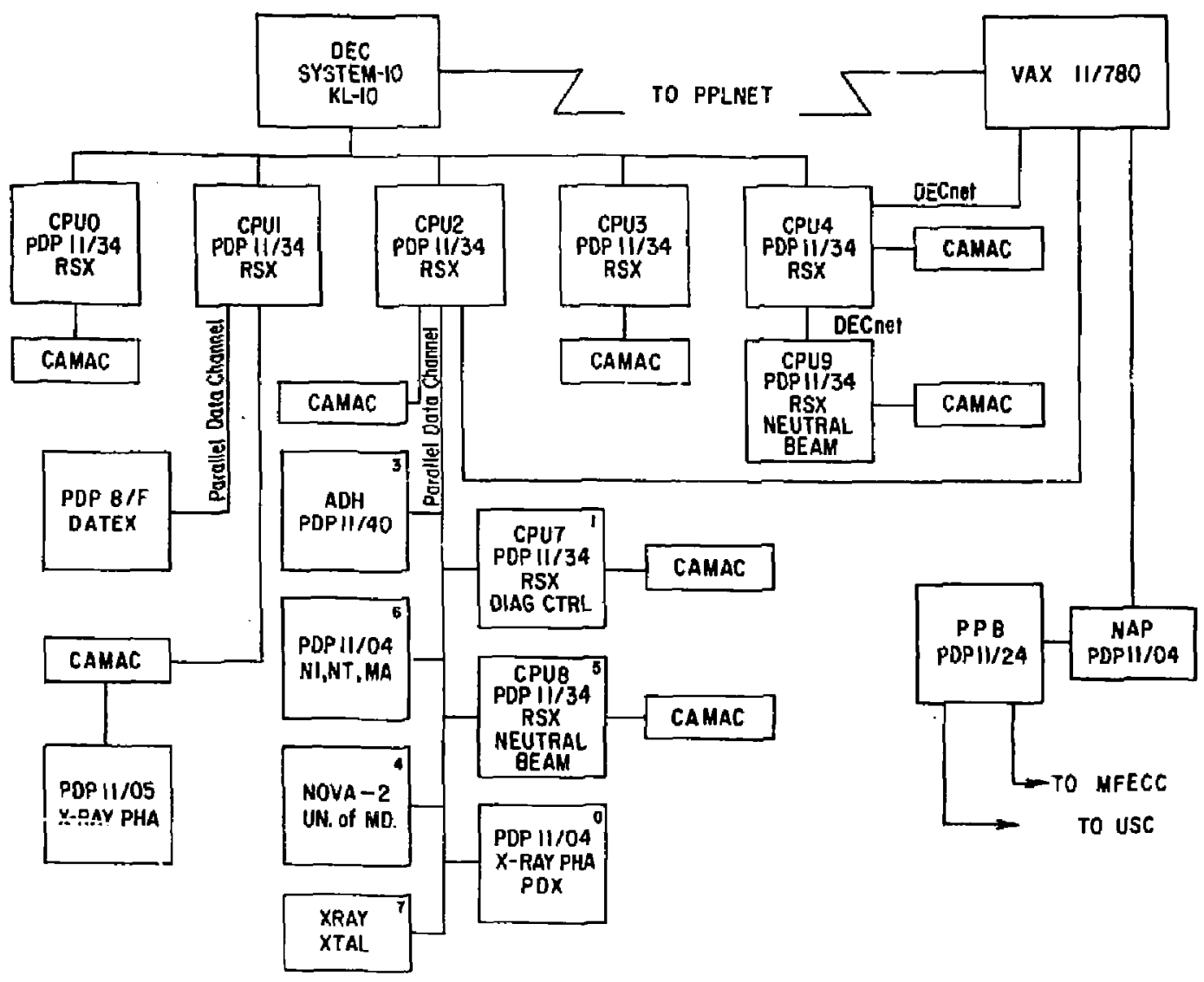

Fig. I 

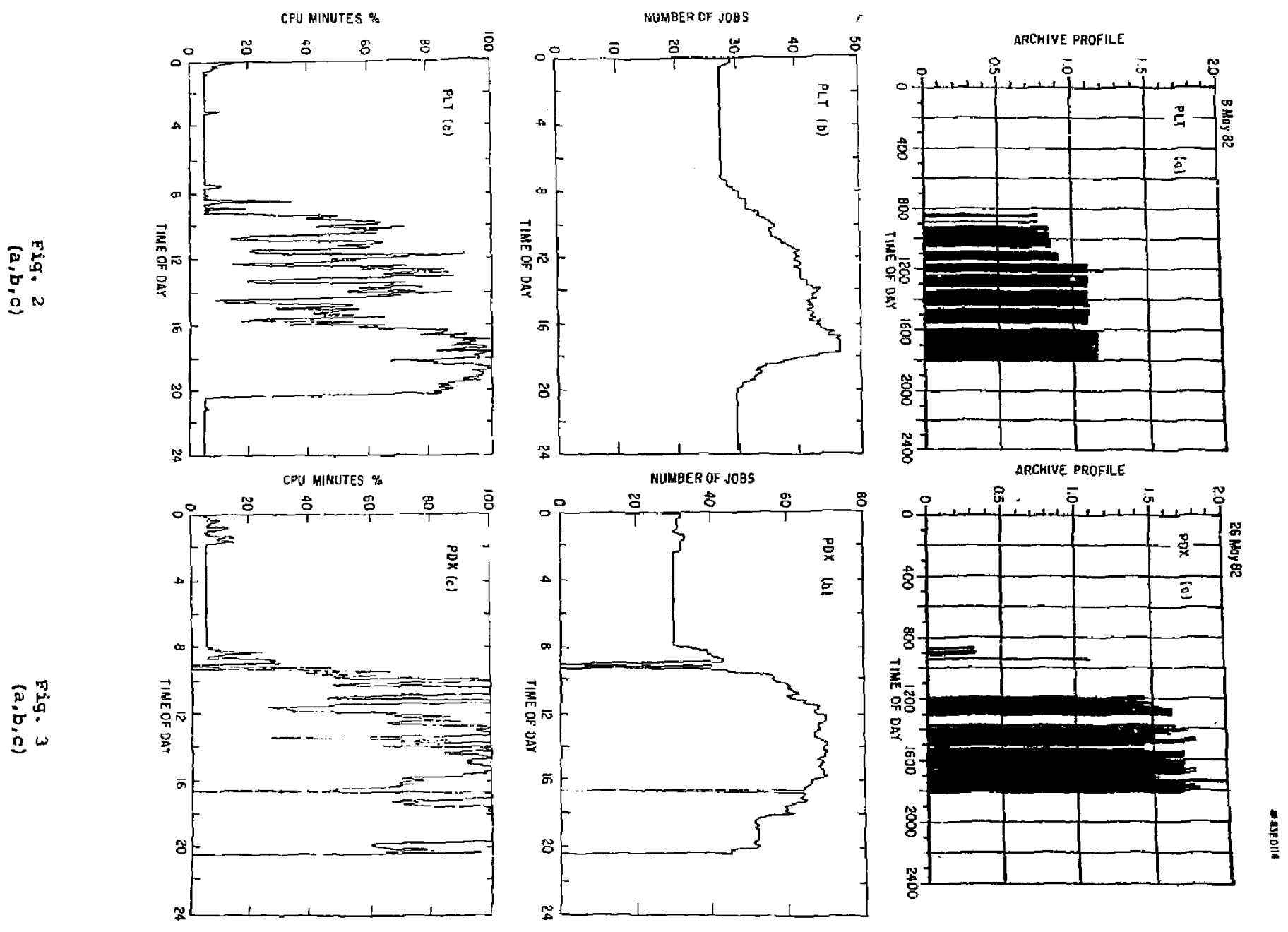

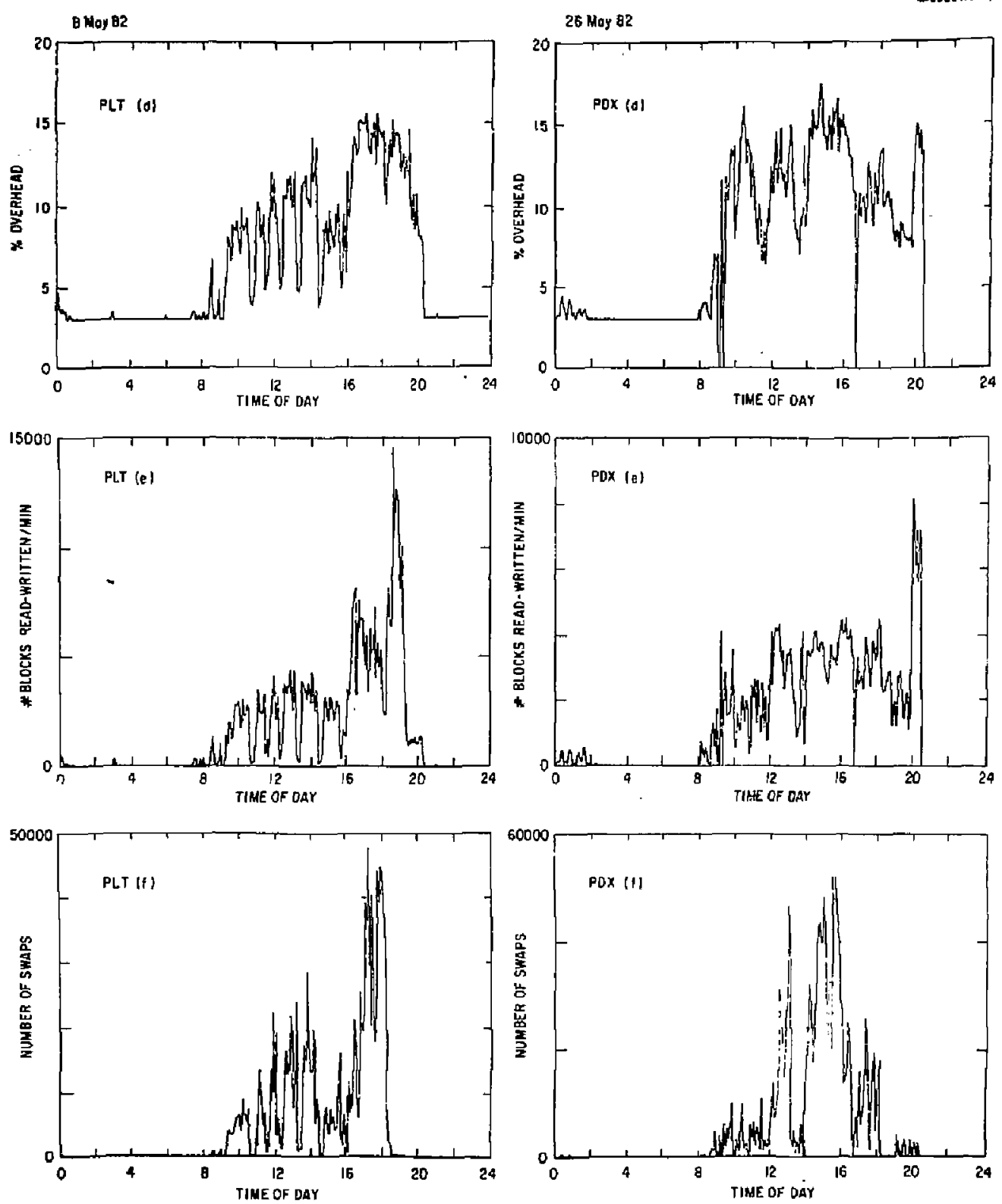

Fig. 2

$\{d, e, f\}$

Fig. 3

$(d, e, f)$ 

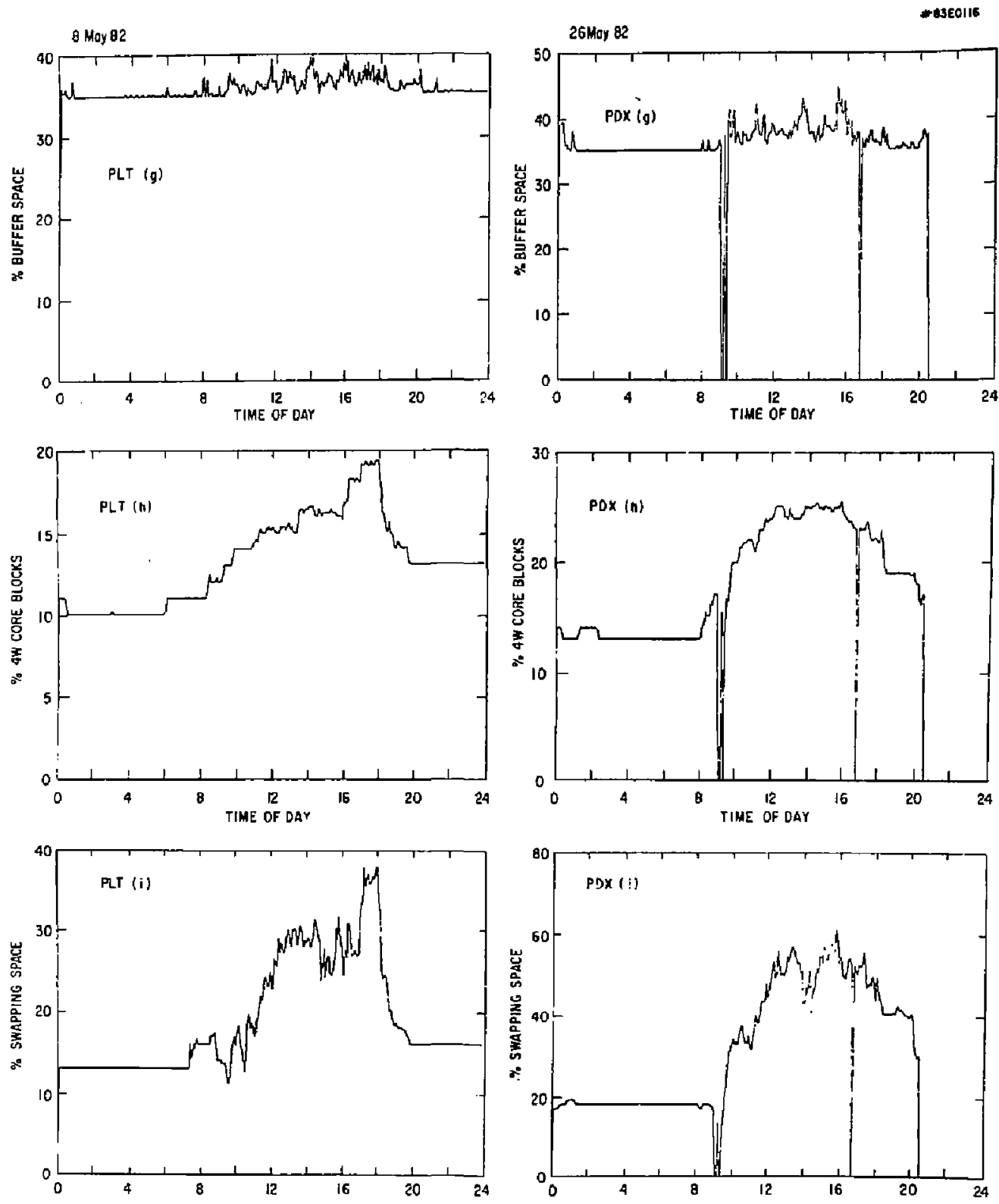

Fig. 2

Fig. 3

$(g, h, i)$

$(g, h, i)$ 
\#83E0107

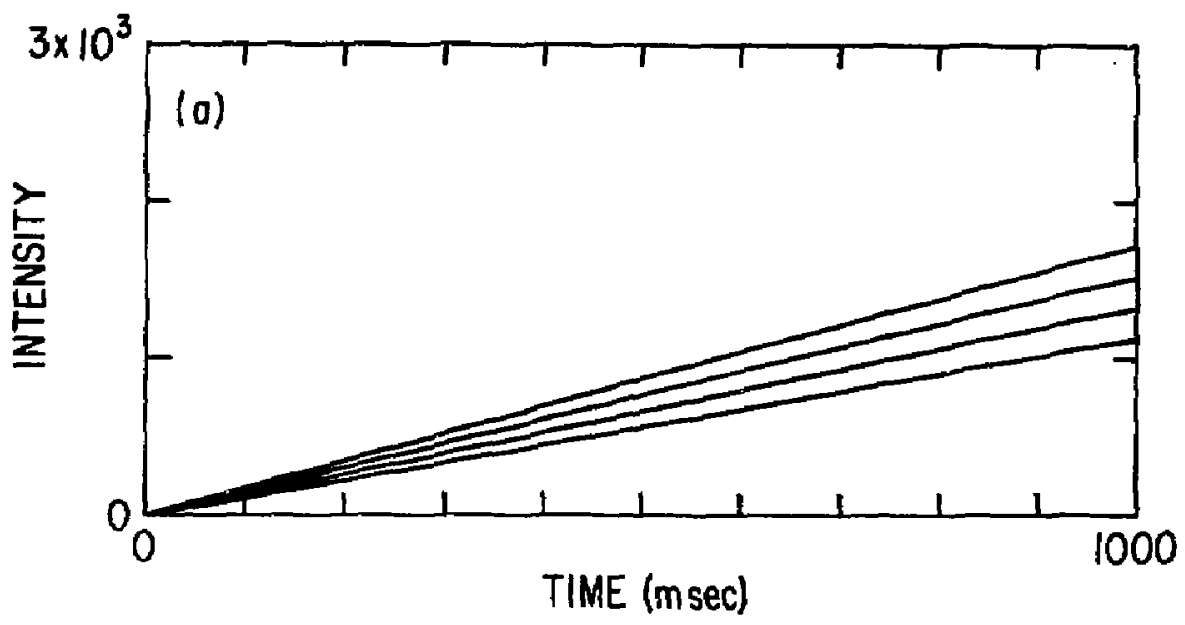

(b)
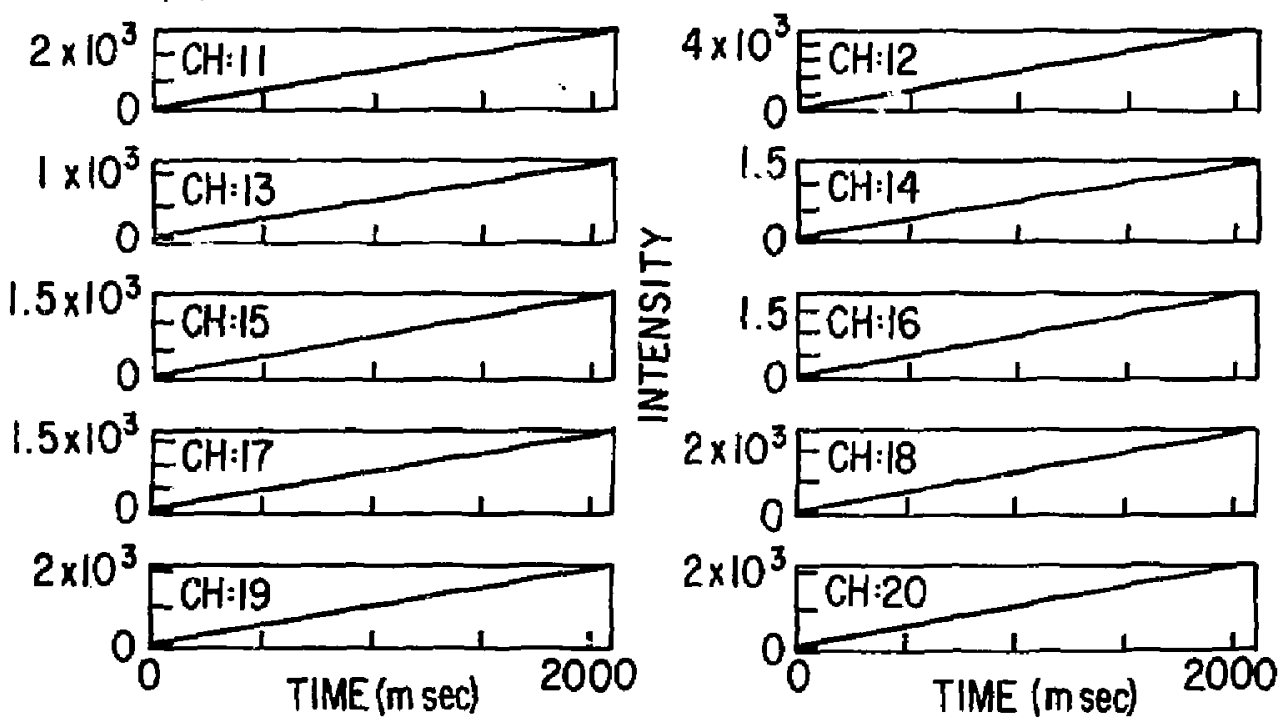

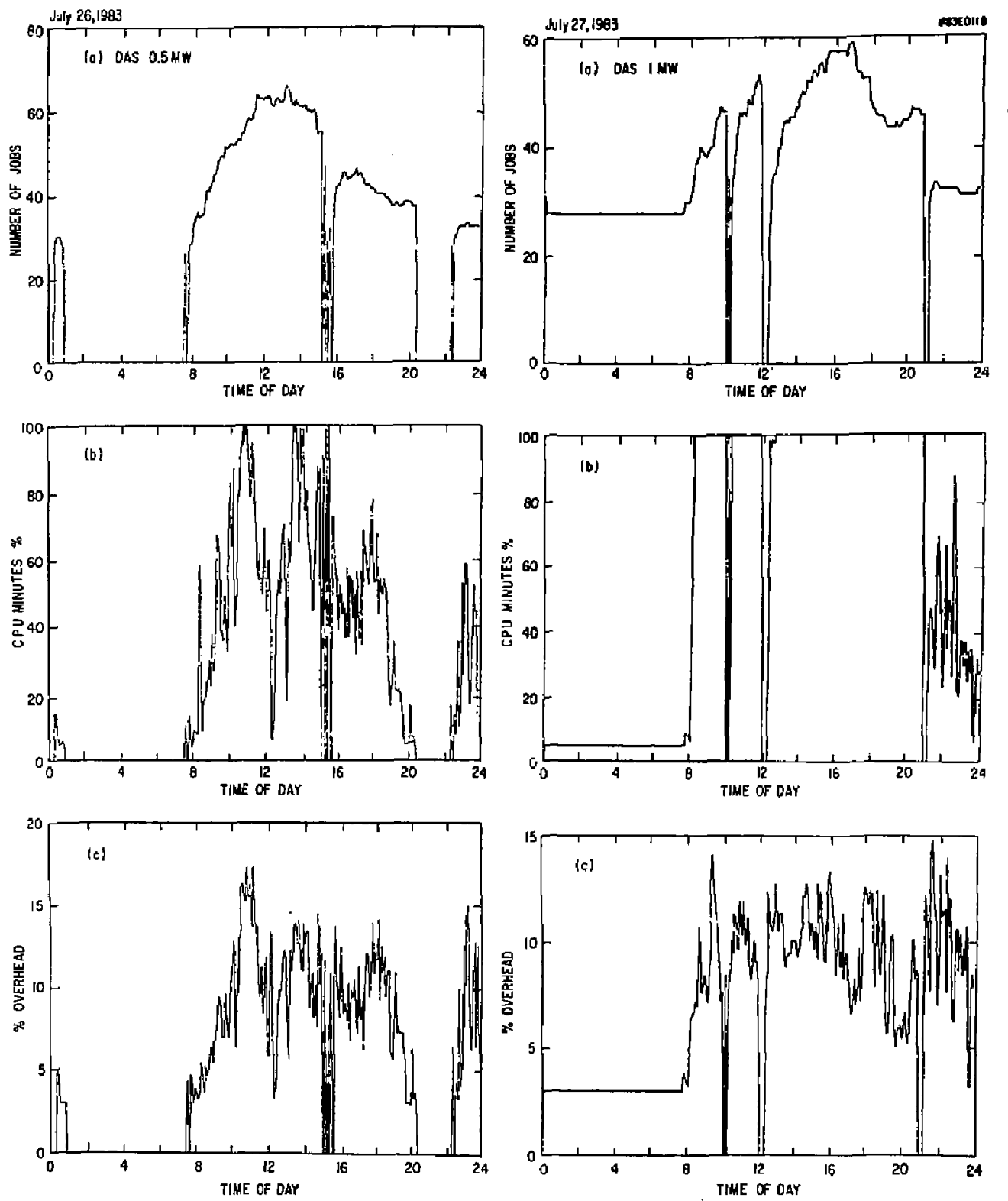

Fig. 5

$\{a, b, c\}$

F1g. $\epsilon$

$(a, b, c)$ 

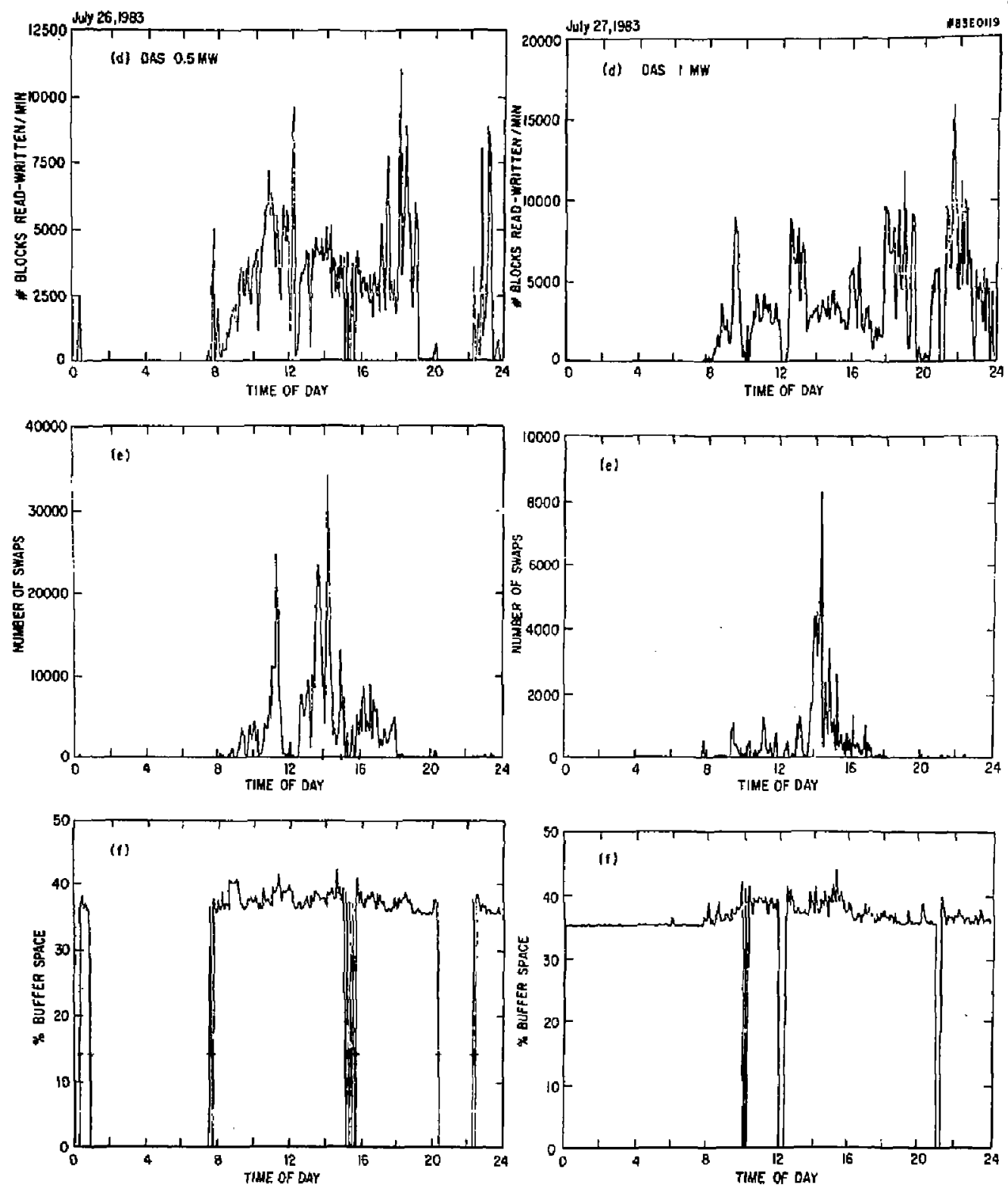

Fig. 5

$(d, E, f)$

Fig. 6

$(d, e, E)$ 

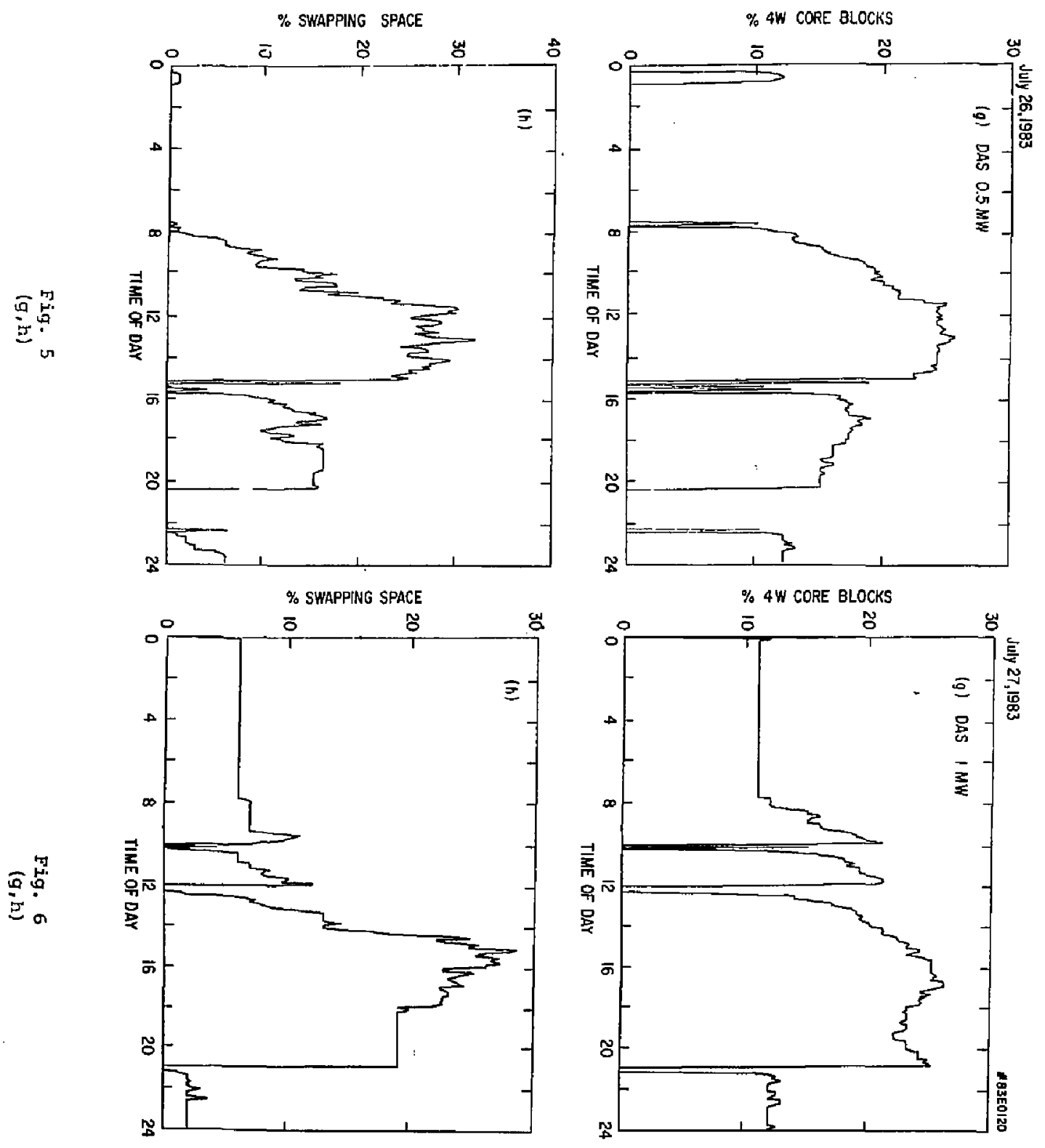

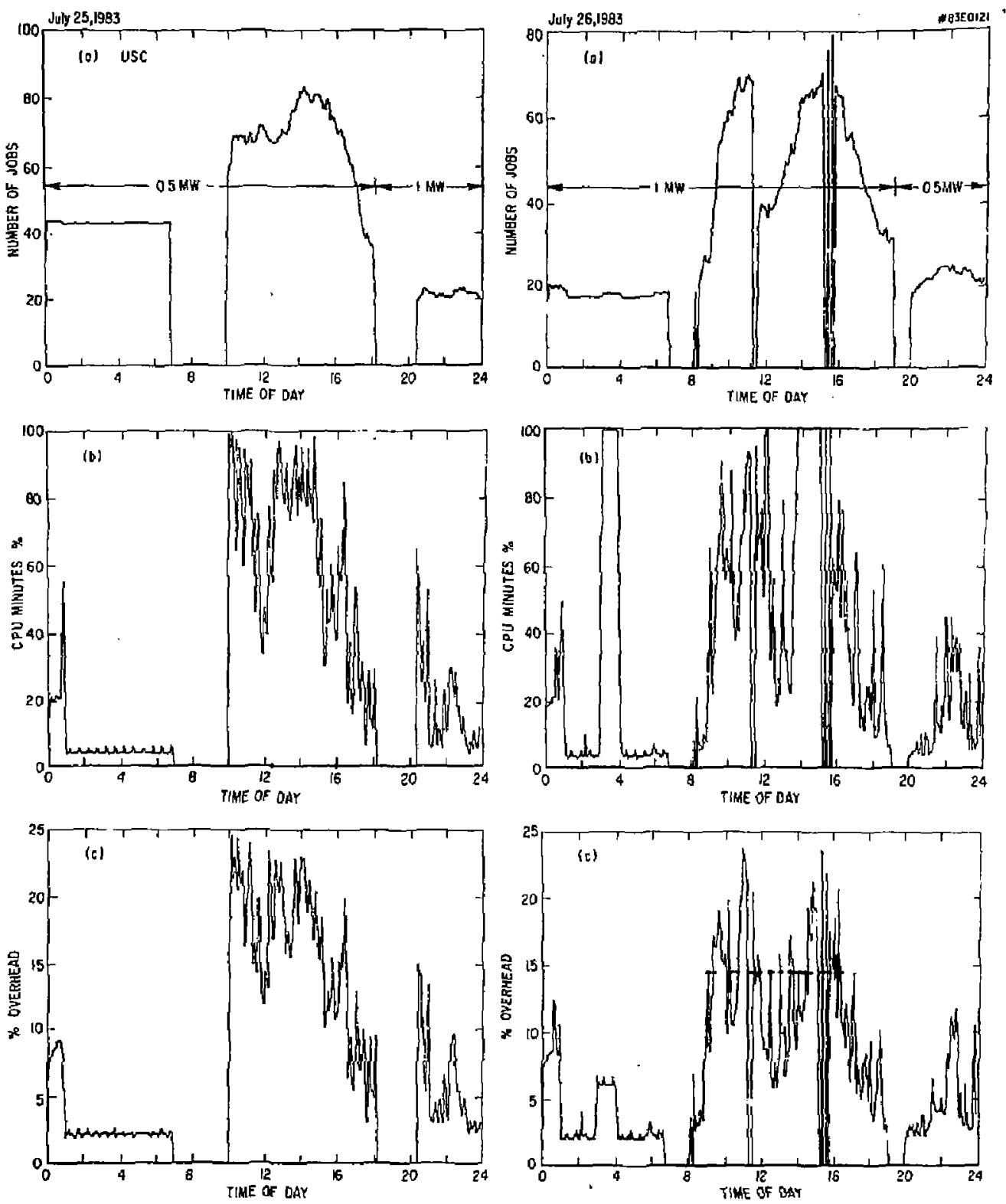

Fig. 7

Fig. 8

$(a, b, c)$

$(a, b, c)$ 

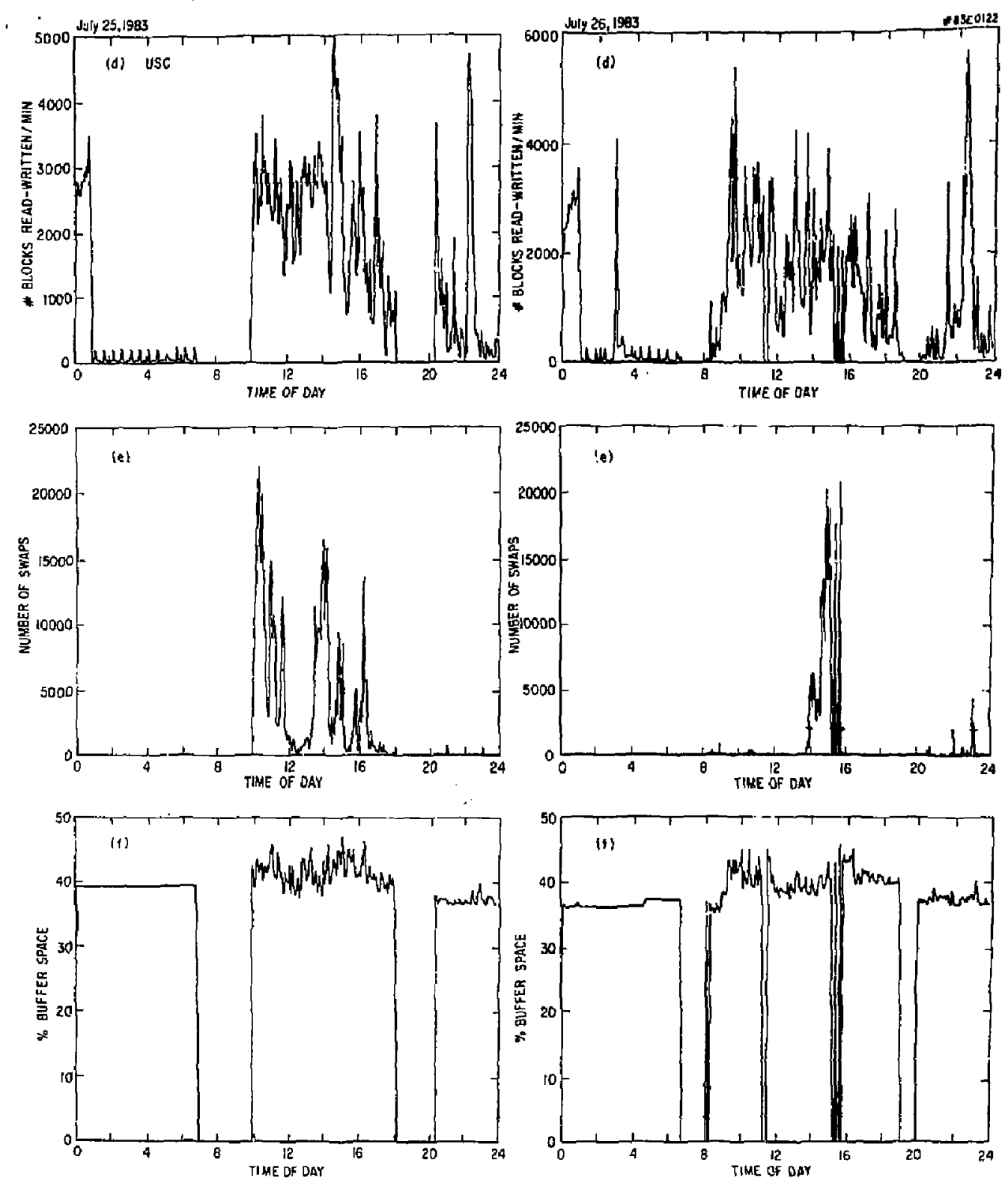

Fig. 7

Fig. 8

$(a, e, f)$

$(a, e, f)$ 

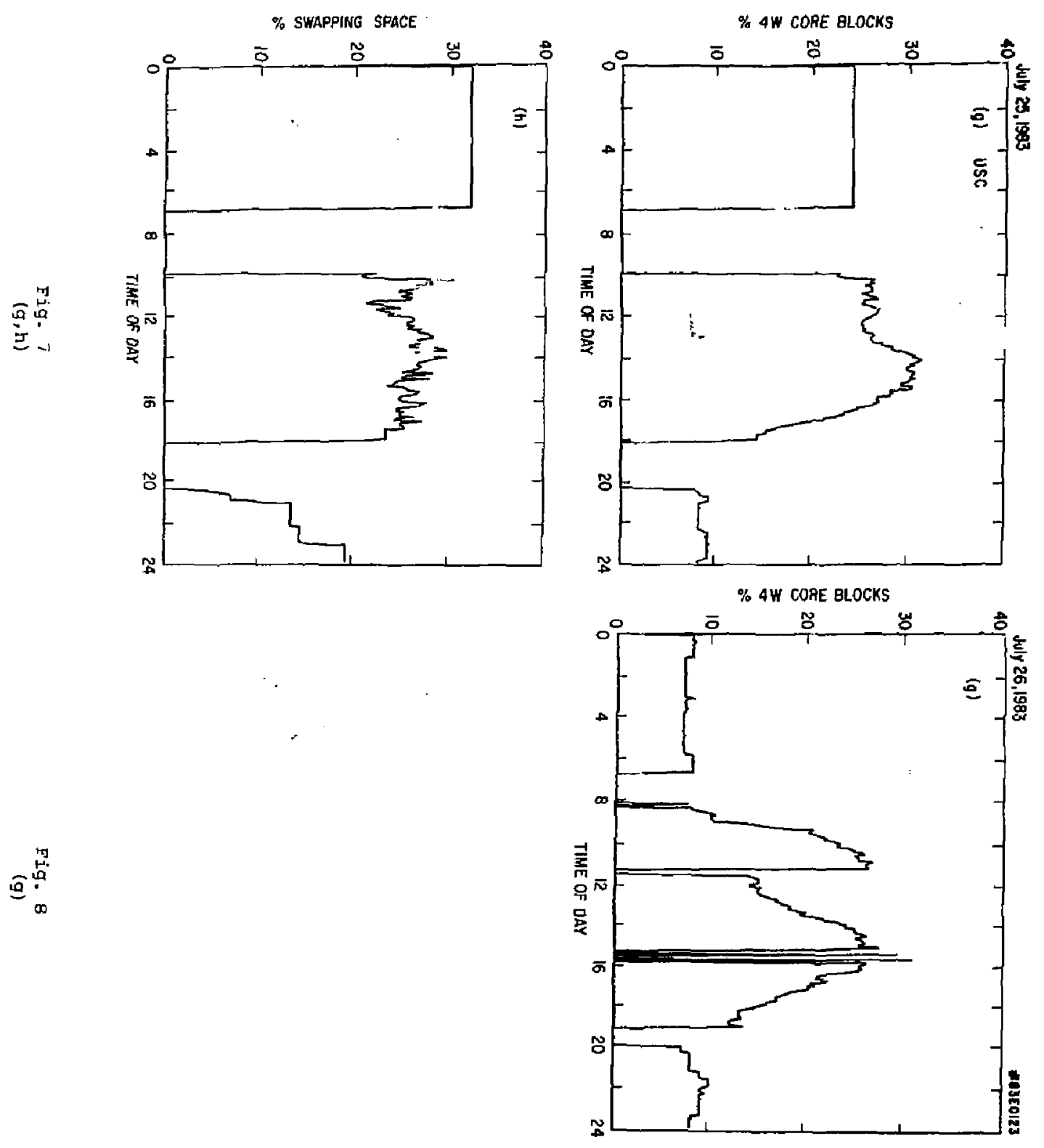

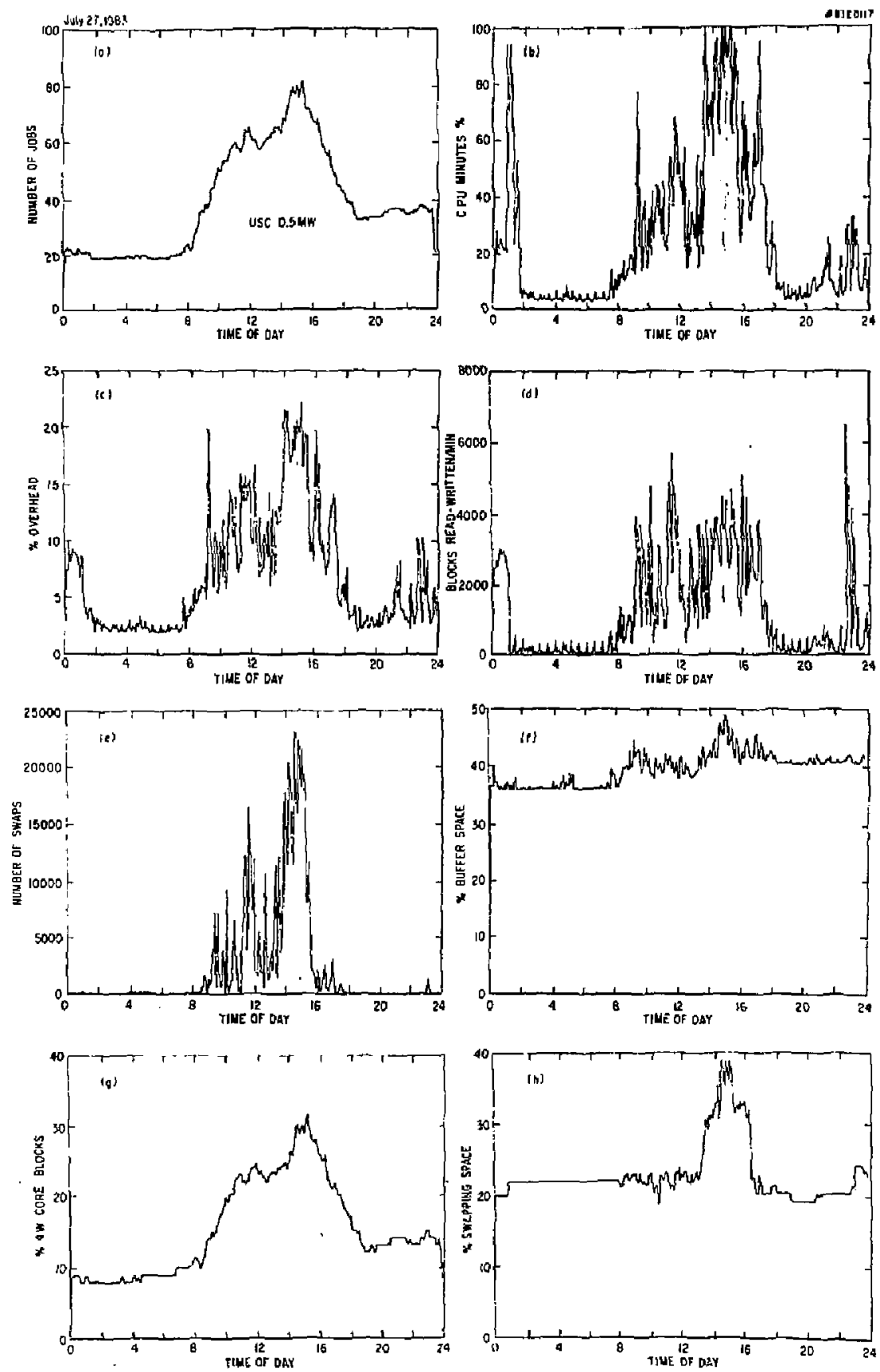

Pig, 9 

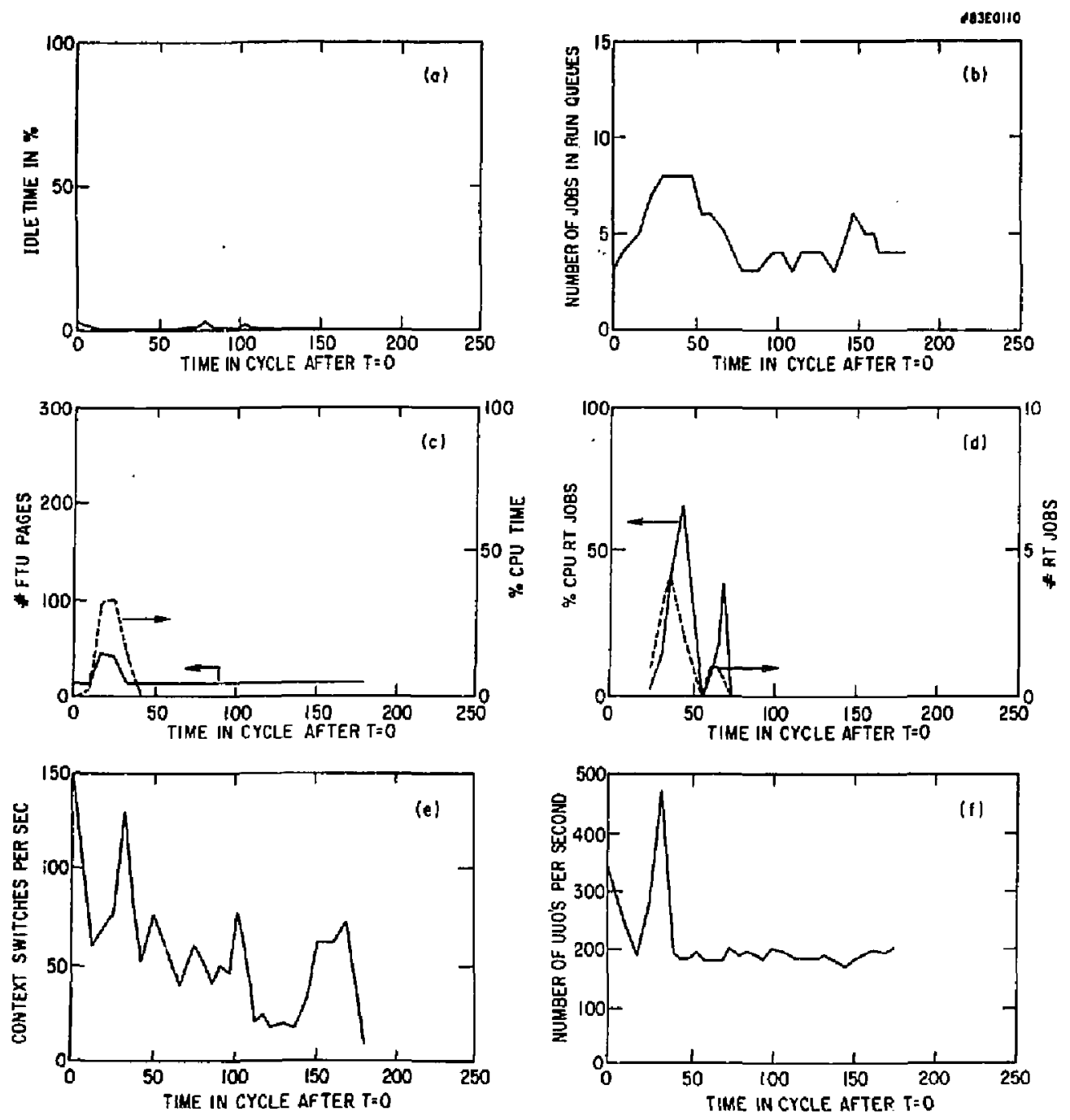

Fig, 10 

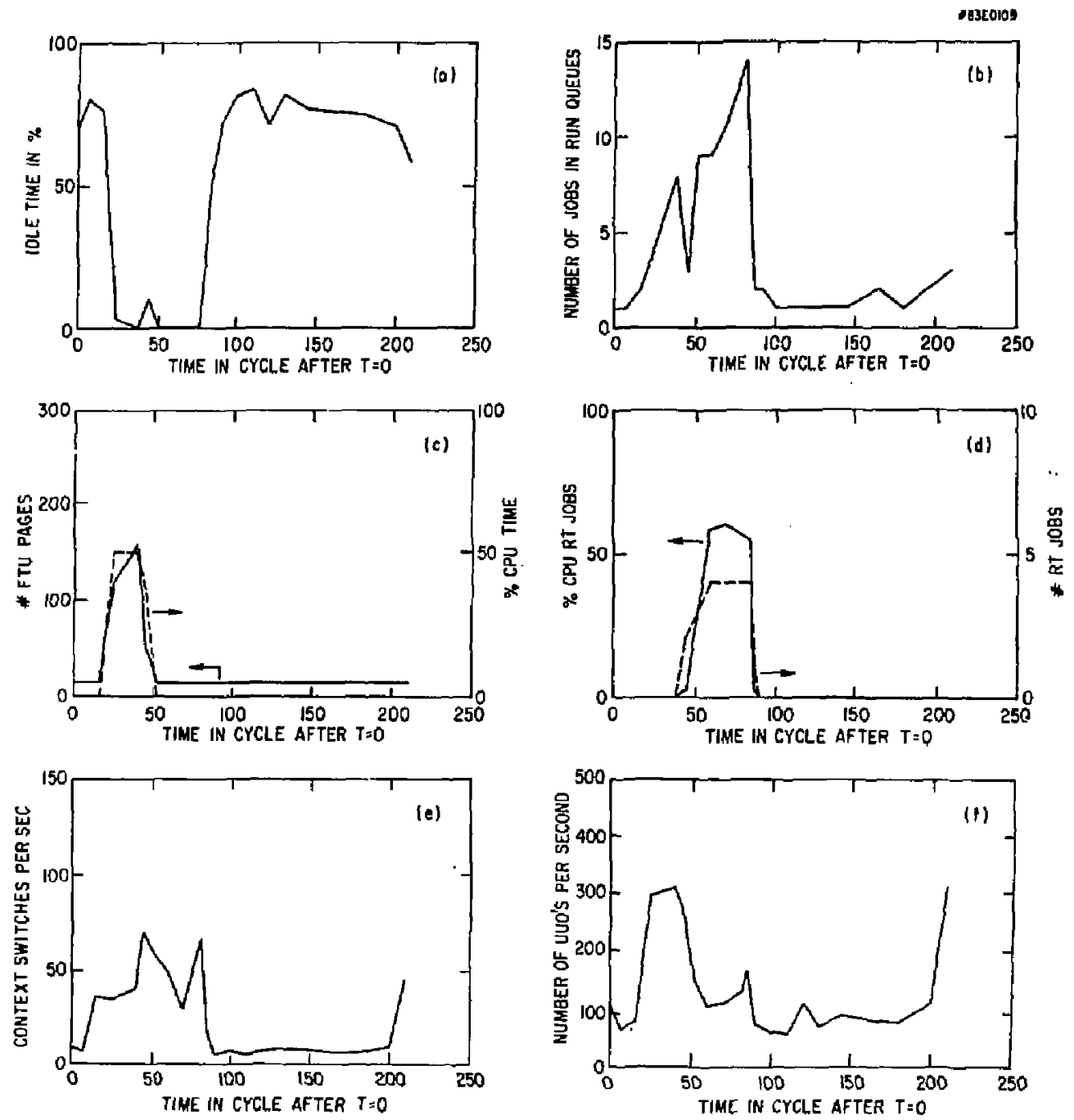

Eig. 11 

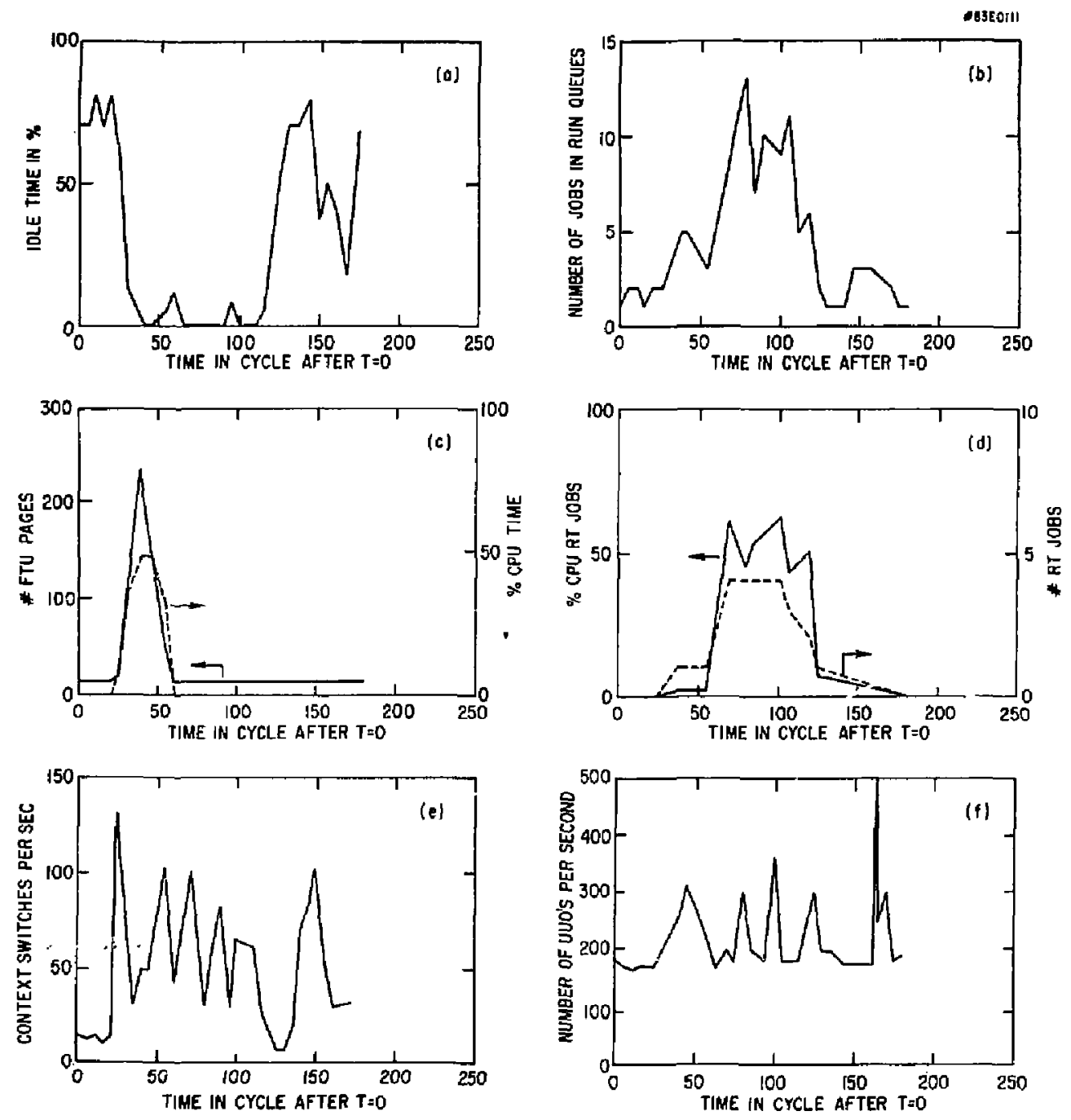

Fig. 12 

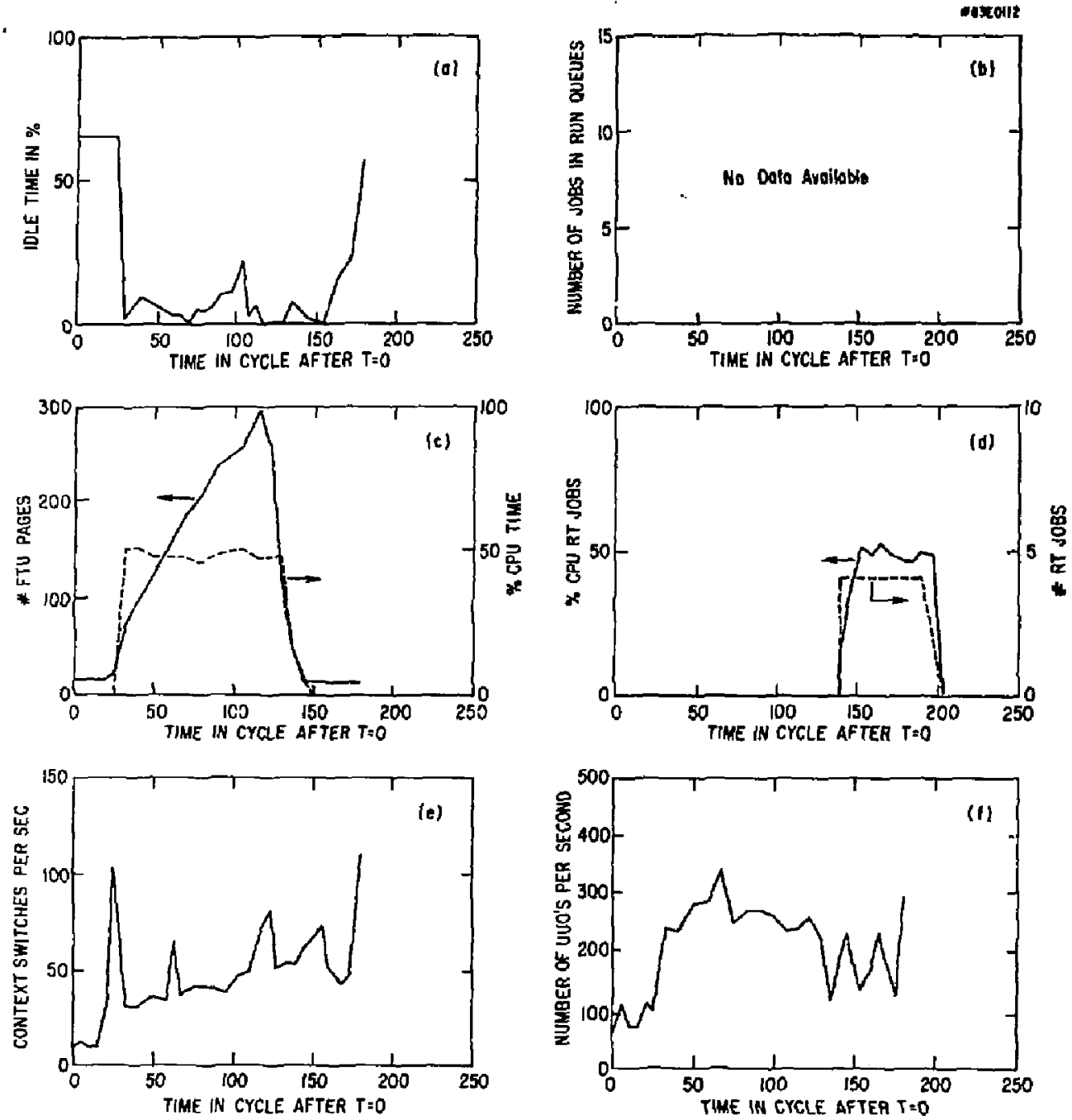

Fig. 13 

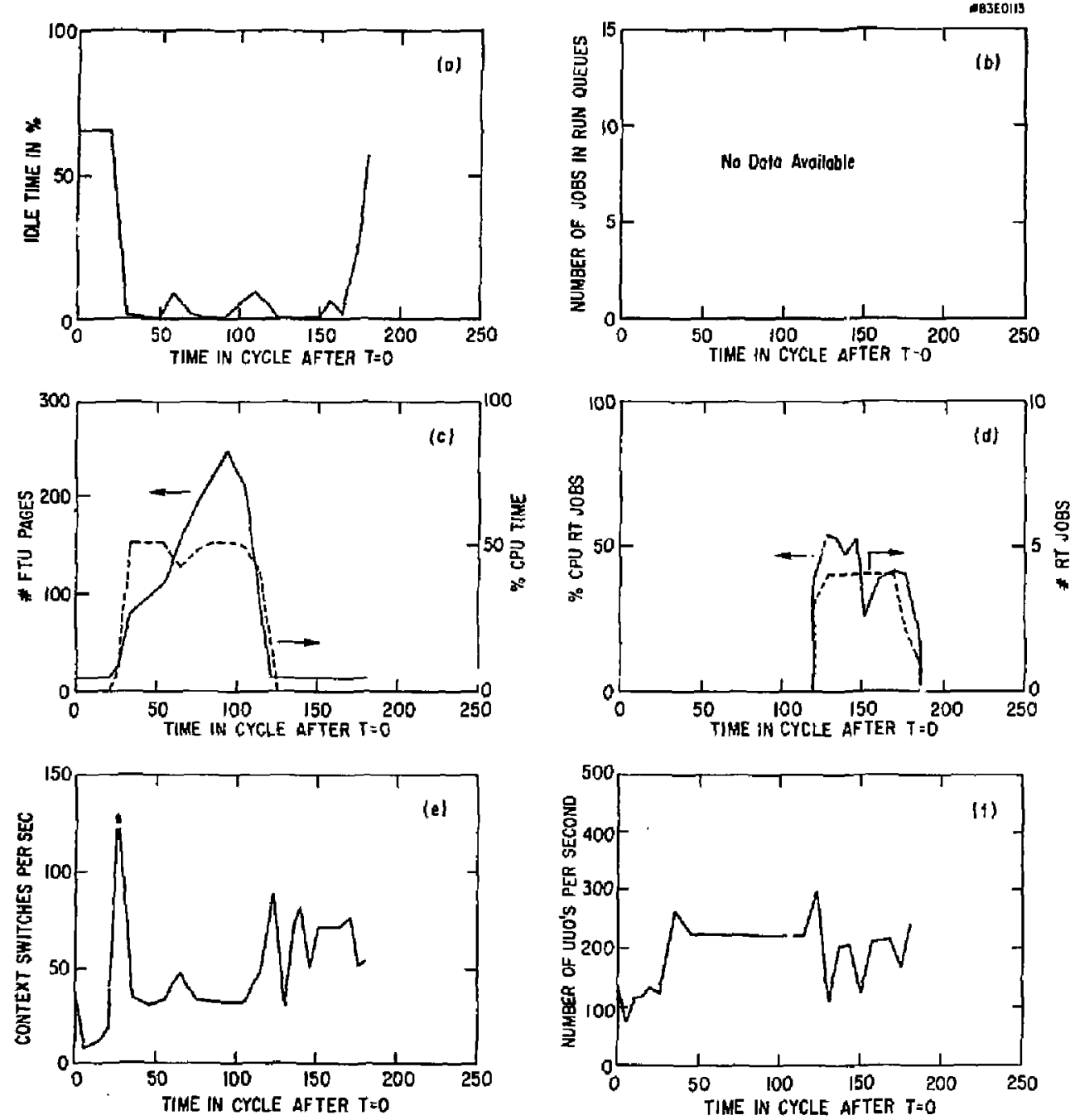

Fig. 14 
\#83E0106

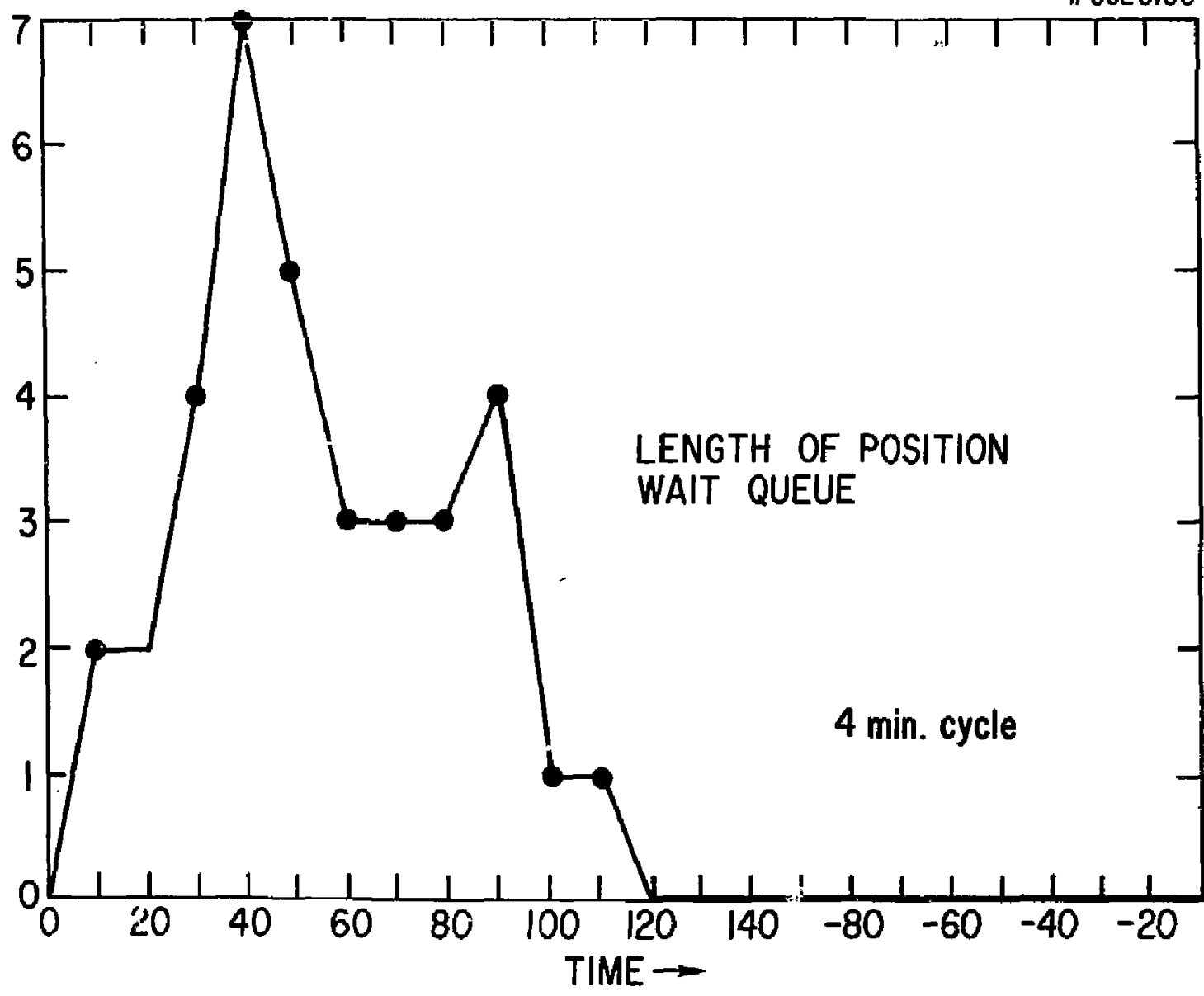




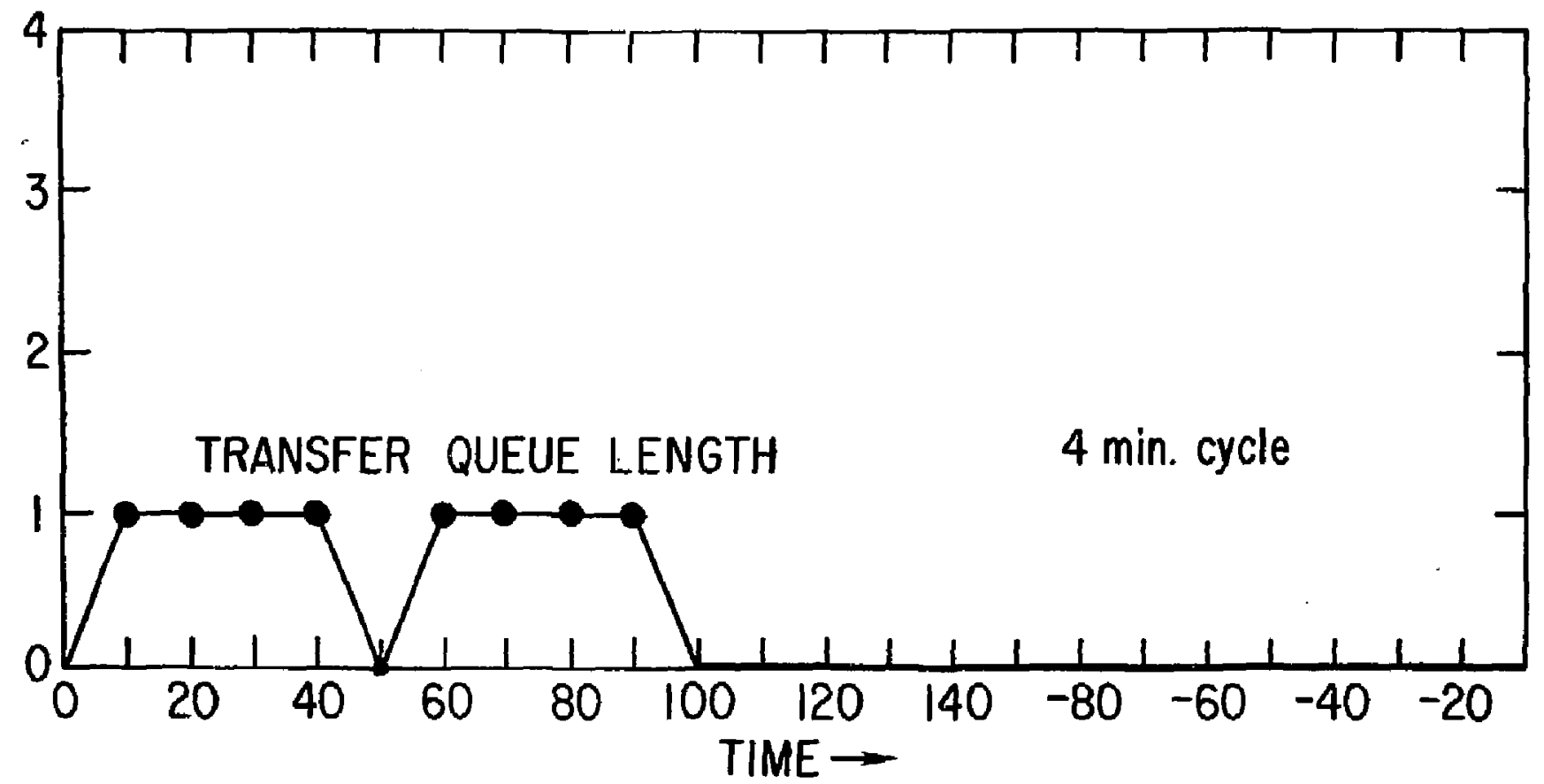


Plasire Res Lab, Austra Mot'I UnIv, AUSTRAliA Or. Fronk J. Paolonl, Unit of Wollongong, MustrullA Prot. I.R. Jones, Fllinders Univ., AUSTRALIA Prot. M,H. Brennan, Unlu Sydney, austrul IA Prof. F, Cop, Inst Thoo Phys, AustR IA Prof, Frank Verhoest, Inst throretIsche, BELGIUM Dr. D* Palunbo, Dg XIl fuslon Prog, BELGIIM Ecole Royale Mlititaleo, Lab de Phys Plasass, BeLgilu Or. P,H, Sakanaka, UnIv Estadual, BRhzIL Or. C.R, Jemes, Ualu of Alborta, CanNDA Prof. J. Teichmann, Univ of Montrael, CANkOA Dr. H.M. Skarsgard, Unlv of Soskatchewan, CANADA Prof. S.R. Sreenlyasen, Universlity of Colgary, CANADA Prof. Tudor W, Johnston, INAS-Energle, CNNDA Dr. Hannes Barnard, Unly British Columblo, CAMABA Dr. M.P. Bachynskl, PPB Technalogies, Inc, , CANADA zhengw LI, SW Inst Physlcs, CHINR

Llarary. Ts Ing tha UnIversIty, CHIMA

Llorarlan, Institute of Physles, CHINh last Plasuse Phys, Acodenta SInica, CHIM Or. Peter Lukae, Komenskeho Unly, CZECHOSLOVAKIA The LIbrarlan, Culham Leborotory, ENGLND Prof. Schotzasan, Observatolro de Hice, fRakCE J. ROAdBT, CEN-EP6, FRANCE AM Dupes LIbrary. AM Dupas Library, FRAKCE Dr. Tom Mual, Acaderty Bl bliographic, HONG KONG Praprint Library, Cent Res Inst Phys, humgatey Dr. S.K. Trehen, Panjab UnJucersity, INDIA Dr. Indra, Mohan Lai Oas, Bararas HIndu Univ, INOIA Dr. L.K. Chovda, South Gujarat Univ, INDIA Dr. R_K. ChhajIanl, Yor Ruchi Marg, INDIA P. Kow, Physlcal Research Lab, INDIA Or. Phlillip Rosenav, Israel inst Tech, ISRAEL Prof, 5, Cuparmen, Tel Aviv Untuersity, ISRAEL Prof, G, Rostagn I, Univ DI Padova, ITALY LIbrarlan, Intil Ctr Theo Phys, IThLY Miss Clelio De Palo, Assoc ElRATOM-CNEN, ITALY Bibl loteca, del ONR EURATOM, ITALY Dr. H. Yamsta, Toshibe Res i Dew, JAPXN Prot. M. Yoshikews, JAERI, Tokai Res Est, MAPA trot. T. Uenidt. Universlty of Tokro, JAPAN Reseorch Into Center, Nogoya university, MPAN Prot. Kyoll NIshlkava, Univ of Hiroshima, IAPAN Prot. Sigeru Mor1, JAERI, JAPAN LIbrary, Kyote Univarsity. JAPAN Prof. Ieh I ro Karakaml, Nithon Un IV, JAPAN Prof. Sotoshl Itoh. Kyushu Unlworslty, JAPAN Tech Into Division, Kores Atomic Energy, KOREA Dr. R, England, Cludad Univarsitarla, MEXICO Bibliotheek, Fcm-l nst Voor Plasmb, METHERLANDs Prot. B.S. Llley, Unlversity of Walkato, NEw ZEALAMD Dr. Suresh C. Shormo, Unity of Celabar. NIGERIA
Prof. J.A.C. Gabral, Inst Suporlor Toch, PORTuGAL Or. Octovian Patrus, ALI CUIA University, RowwiA Prof. HA. Hol Iberg, Unlvarsity of Notal, SO AFRICA Dr. Johen de Villlers, Atomic Enorgy Bd, so AFRICA Fus Ion DIY, LI Lrory, IEN, SPAIN Prof. Hons wilholeson, Chalmors Unlv Tech, SWEDEN Or. Lennert Stent10, University of UKEA, SWEOEH Library, Royal Inst Toch, SIEDEN Dr. Erik T. Karlson, Uppsale Universitat, SWEOEN Centre do Recherehesen, Eeole Polytech fod, SWITEERLAND Or. H.L, Wolsa, Mat'l Bur Stand, USA

Dr. W.M. Stacey, Georg Inst Tech, USA Dr. S.T. Wh, Uת IV Alabana, USA

Prof. Normen L. Oleson, Univ S Florlda, USA

Dr. Bonjainin Mo, lawe State Unlv, USA Prof. Magne Kristlansen, Tokos Teeh Univ, USA Dr. Raymond Askew, Auburn Univ, USA Or. V.T. Tolox, Kharkov Phys Tect, Ins, USSR Dr. D.D. Ryutov, Slborlan Acad Sel, USSR Dr. 6.A. Ellseev, Kurchatov Institute, US5R Dr. V.A. Glukhikh, Inst EJectro-PhysIenI, USSR Instltuto Gon. Physlas, ussR

Prot, T,J. Boyd, UnIv col lage N Walos, waLES Dr. K. SchIndlar, Ruhr Univarsitot, W, EERHANy Huclaar Ros Estab, Jullach LTd, W. GEFanNY Librarlan, Max+lanck instltut,, , GEFAANY Dr. H.J. Kaeppler, Unlverslty Stuttgart, W. GEPOAAYY Bibl lothak, Inst Plasmatarsenung, W. GERANY 